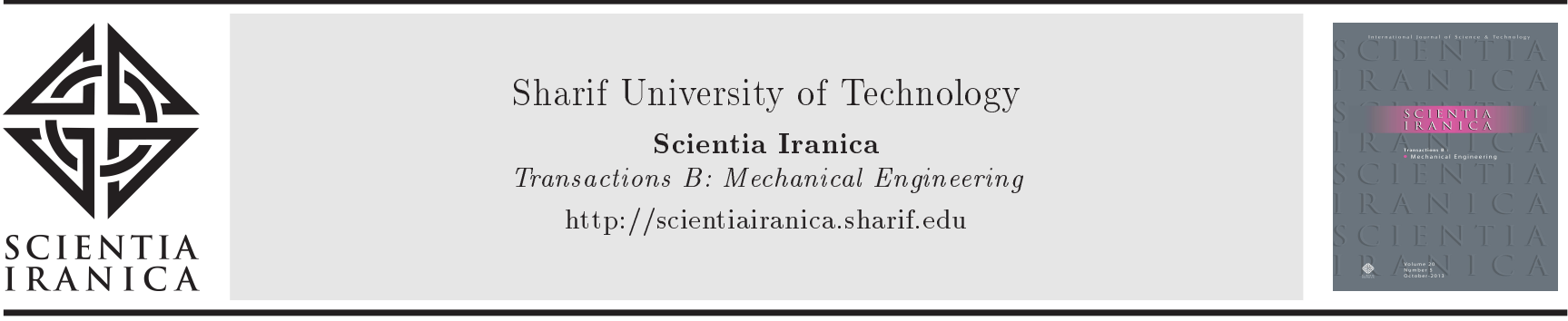

\title{
Numerical prediction of deflection and stress responses of functionally graded structure for grading patterns (power-law, sigmoid, and exponential) and variable porosity (even/uneven)
}

\author{
P.M. Ramteke ${ }^{\mathrm{a}}$, K. Mehar ${ }^{\mathrm{b}}$, N. Sharma ${ }^{\mathrm{c}}$, and S.K. Panda $\mathrm{S}^{\mathrm{a}, *}$ \\ a. Department of Mechanical Engineering, National Institute of Technology Rourkela, Rourkela - 769008, Odisha, India. \\ b. Department of Mechanical Engineering. Madanapalle Institute of Technology and Science, Madanapalle - 517325, Andhra, \\ Pradesh, India. \\ c. School of Mechanical Engineering, KIIT (Deemed to be University) Bhubaneswar, Bhubaneswar - 751024, Odisha, India.
}

Received 20 April 2020; received in revised form 19 May 2020; accepted 29 June 2020

\section{KEYWORDS}

Functionally graded

materials;

Bending;

HSDT;

Porosity;

Grading pattern.

\begin{abstract}
This paper introduces the finite element solutions of static deflection and stress values for functionally graded structures by considering variable grading patterns (powerlaw, sigmoid, and exponential), including porosity effect. Unknown values are obtained through computations via a customized computer code using cubic-order displacement functions considering the varied distributions of porosity (even and uneven) through the panel thickness. Also, the values are simulated through design software (ANSYS) to establish the present numerical solution accuracy. The comparison and the element sensitivity behavior of the present numerical model are verified by solving different kinds of numerical examples available in the published domain. At last, the effects of several geometry-related parameters (aspect ratio, curvature ratio, thickness ratio, porosity index, type of porosity, power-law exponent, geometrical configuration, and support conditions) affecting the structural stiffness and the corresponding outcomes (deflection and stress) of the Functionally Graded (FG) structure are evaluated and measured using the proposed numerical model.
\end{abstract}

(C) 2021 Sharif University of Technology. All rights reserved.

\section{Introduction}

Functionally Graded Materials (FGMs) are known as the advanced form of the layered composite structure with an adequate variety of material composition, i.e.,

*. Corresponding author. Tel.: +916612462529

E-mail addresses: 518me1020@nitrkl.ac.in (P.M. Ramteke); kulmanimehar@mits.ac.in (K. Mehar);

nitin.sharmafme@kiit.ac.in (N. Sharma);

pandask@nitrkl.ac.in (S.K.Panda)

doi: $10.24200 /$ sci. 2020.55581 .4290 metal to ceramic. The variation of constituents is achieved numerically via a different mathematical form and named according to the pattern type. Out of all grading types, three major types of grading patterns, i.e., power-law (PWL-FGM), exponential (EXPFGM), and sigmoid (SIG-FGM) [1], are adopted for structural implementations. It is of significance to mention that the porosity within the part component may reduce the total structural strength and/or stiffness and the subsequent performances of the components. Therefore, the effects of porosity on the numerical modeling for graded structural analysis represent one of 
the important parameters that could not be neglected. Moreover, previous studies demonstrate that the variable distribution pattern of porosity, i.e., even and uneven types [2], may considerably affect the structural responses.

Researchers have investigated Functionally Graded (FG) structures numerically to predict the structural responses (bending, vibration and buckling) by using either established or modified displacement kinematic theories. In this respect, a number of relevant studies are briefed here to find the necessary knowledge gap in this present context. To this end, a Three-Dimensional (3D) elasticity solution is employed [3] to express the bending strength of FG plate structures under transverse loading. The Static responses of all Sides Simply Supported (SSSS) functionally graded rectangular plates were considered using generalized Shear Deformation Theory (SDT) [4] subjected to transverse mechanical loading. Similarly, the effect of coating on structural stiffness and subsequent deflection parameters of the graded plate under the influence of transverse loading was reported [5] by considering the sigmoid type of grading through the panel thickness. Moreover, the static deflections of thick elastic SIG-FGM $\left(\mathrm{Al}_{2} \mathrm{O}_{3} / \mathrm{Al}\right)$ beam under the effect of uniformly distributed transverse loading were reported [6] considering the nonvariant type of Poisson's ratio. The 3D Finite Element (FE) solutions of the static deflection values of FGM flat components due to the variations of aspect ratio were simulated [7] for different grading rules, i.e., PWL-FGM, SIG-FGM, and EXP-FGM. Subsequently, to improve the modeling efficiency, Carrera's Unified Formulation (CUF) was proposed and utilized to analyze the FG structure under the combined thermo-mechanical loading [8]. Also, the CUF-type kinematic model was adopted to evaluate deflection values for the unidirectional FG structure [9]. In addition to different modified kinematic models, the First-order Shear Deformation Theory (FSDT) model [10] was also adopted to compute the bending and free vibration responses of the FG plate. Further, to maintain the shear stress continuity, the Higher-order Shear Deformation Theory (HSDT) [11] kinematic model has drawn much attention of different researchers following the report of Reddy on measuring different responses, i.e., eigenvalue solutions and static bending responses of the FG structure. Similarly, Finite Element Method (FEM) is the most common type of the numerical tool utilized to model and predict the bending and free vibration frequency behavior of FG structures, i.e., trapezoidal plate reinforced with Graphene Nanoplates (GNPs) [12]. The smooth cell-based three-noded plate element in conjunction with the FSDT is utilized to compute the values of static and dynamic deflection of the FG plate [13]. Similarly, the Finite Strip Method (FSM) [14] was extended to analyze the buckling behavior of the FG plate under the in-plane compressive loading. Subsequently, a new quasi-3D Hyperbolic SDT (HySDT) model was established [15] to compute vibration and deflection responses of the graded plate-type structure. Also, the simple FSDT integrated with the mesh-free moving Kriging method was developed [16] to compute the static bending and free vibration responses of the FGM structure. To determine the enhanced frequency values of the nanotube-reinforced graded structure [17], variable distribution was considered through the thickness of the plate via the FSDT model. Similarly, the graded Carbon Nanotube (CNT) reinforced composite spherical shell structure frequencies [18] were obtained using Sander's type shell kinematics in conjunction with the FSDT. The dynamic buckling responses of the viscoelastic nanocomposite laminated conical shell subjected to magneto-hygrothermal load were reported [19] using FSDT. Also, the frequency was controlled using smart material concept [20] for the laminated sandwich shell components with piezoelectric layers via the layer-wise FSDT. The Eigen characteristics of the FG nanoplates were performed [21] considering the nonlocal Trigonometric SDT (TrSDT) to predict the accurate responses. Similarly, the quasi-3D TrSDT for plates including the thickness stretching effect was utilized to obtain frequency responses [22] of the FG plate. A size-dependent mesh-free model was derived [23] in the framework of the HSDT and the nonlocal Eringen's elasticity theory to obtain the static deflection and frequency responses of the FG CNT-reinforced composite nanoplates. The bending, free vibration, and mechanical buckling behaviors of the FGM plates were illustrated [24] using a newly developed HSDT model. Also, a single-variable refined plate theory was established [25] to compute the static bending data of the FG plate component. The effect of size on the deflection values of the FG curved nanobeams was reported [26] using the Timoshenko beam theory considering a stress-driven nonlocal integral model. Vibroacoustic analysis of the doubly curved thick shells was carried out in $[27,28]$ based on the 3D sound propagation approach and state space solution. Also, the acoustic analysis of sound transmission loss through infinite FG thick plate and laminated composite plate was carried out [29,30] using HySDT and two-variable refined plate theory. The shear deformation shallow shell theory and third-order SDT were utilized [31-33] to investigate the acoustic behavior of doubly curved composite shells. Also, the refined integral plate theory was used [34-37] to obtain the structural responses (buckling, bending, and vibration) of the FG 
plates and graphene sheets. The static and dynamic behaviors of the FG beams and nanoplates were investigated [38,39] using quasi 3D SDT and HySDT. The hygro-thermo-mechanical buckling responses and thermomechanical bending responses of FG sandwich plates were obtained [40,41] using novel and nth order shear deformation theories. The nonlocal higher-order theory was employed $[42,43]$ for the vibration, buckling, postbuckling, and bending analyses of various structures (annular nanoplate and graphene sheets). The dynamic behavior of Graphene Platelets (GPLs) reinforced nanocomposite sandwich truncated conical shells and FG-CNT reinforced sandwich microplates was investigated $[44,45]$ using various kinematic models (FSDT, HSDT, and exponential SDT). A hybrid analytical-intelligent approach was used [46] to conduct the fuzzy reliability analysis of the composite beams reinforced by Zinc Oxide ( $\mathrm{ZnO}$ ) nanoparticle.

In general, porosity-type defect can be induced in FG structural components while manufacturing, which causes a reduction in the total structural strength and diminishes the reliability of final results. Therefore, a considerable number of earlier published papers relevant to the porous FG structures are discussed in the following. The elastic buckling and static deflection values of shear deformable FG porous beam components were evaluated [47] using Timoshenko beam theory. The static deflection, frequency, and buckling responses of porous FG micro-plates were obtained using classical and FSDT [48] kinematics. Moreover, the Strain Gradient Theory (SGT) was adopted to examine the nonlinear bending and the frequency values [49] of the FG porous tubes. Also, the nonlinear deflections of the FG porous micro/nanobeams reinforced with GPLs were obtained [50] using SGT. Similarly, the effect of porosity on the structural responses (vibration, bending, and dynamic) of different FGMs, i.e., plates resting on elastic foundation and beams, was presented [51-54] by employing various theories (quasi-3D HySDT, nonlocal $n$th order SDT, and sinusoidal SDT).

Following a comprehensive review, it was found that the majority of research studies evaluated the FG structure by considering only PWL-type grading. Also, the effect of porosity and its distribution pattern influencing the final responses of the graded structure have not drawn substantial attention so far. Further, the review indicates that different kinematic models are adopted including the solution techniques to evaluate and measure the responses. The completed researches point to the existence of a substantial gap, i.e., the effect of variable grading pattern in association with porosity in the framework of shear deformation kinematics that did not receive any attention in the past. Hence, the authors attempted, for the first time, to derive a generic mathematical formulation for gradedtype structures with emphasis on all the three types of grading pattern (PWL, SIG, and EXP), variable porosity distribution (even and uneven), and geometrical shape to measure the deflection and stresses using the FE technique in the framework of the HSDT kinematics. In this regard, a specialized computer code is prepared in the MATLAB platform utilizing the isoparametric $\mathrm{FE}$ formulation to compute the deflection and stress parameters. The deflection and the stress responses are compared with the published values to demonstrate the inevitability of using HSDTtype kinematic model including the influences of the grading pattern, porosity, and its distribution. Moreover, the responses are compared with the simulated data obtained via the commercial FE tool (ANSYS) to capture the comprehensive behavior of the proposed model. Finally, static bending and stress responses of different types of FGM structure including the effect of porosity, distribution of porosity, and grading patterns are measured by solving a series of examples and are explained subsequently.

\section{Mathematical formulation}

\subsection{Effective FGM properties}

Firstly, the steps of effective material property evaluation of graded structure are taken by considering the variable grading pattern along the thickness direction $\left(\alpha_{z}\right.$-axis) to achieve the desired FG model. In general, the top and bottom surfaces $\left(\alpha_{z}=h / 2\right.$ and $\alpha_{z}=$ $-h / 2)$ of the FG panel are considered ceramic and metal-rich, respectively. Further, the elastic property variation has been obtained numerically using the available methodologies, i.e., Voigt's model (simple rule of mixture) in association with the volume fractions of material along the thickness direction. In the following subsection, material property variations of three types of grading pattern, i.e., PWL-FGM, SIG-FGM, and EXP-FGM, with and without porosities (even and uneven) are deliberated.

\subsection{1. $P W L-F G M$}

According to PWL-kind grading, the elastic property variation [1] through the thickness direction can be expressed as follows:

$$
P=\left(P^{c}-P^{m}\right) V_{f_{c}}+P^{m} .
$$

Now, the desired porosity including the distribution types [2], i.e., even and uneven types, is presented in the following equations. Of note, the density of porosity is high in the middle region of the cross-section and decreases linearly towards the top/bottom surface for the uneven distribution [55].

$$
P=\left(P^{c}-P^{m}\right) V_{f_{c}}+P^{m}-0.5 \lambda \times\left(P^{c}+P^{m}\right),
$$




$$
\begin{aligned}
P= & \left(P^{c}-P^{m}\right) V_{f_{c}}+P^{m}-0.5 \lambda \\
& \times\left(P^{c}+P^{m}\right)\left(1-\frac{2\left|\alpha_{z}\right|}{h}\right),
\end{aligned}
$$

where $V_{f_{c}}=\left(0.5+\frac{\alpha_{z}}{h}\right)^{n_{z}}$ and $V_{f_{m}}=1-V_{f_{c}}$.

The FG panel geometry is shown in Figure 1, whereas Figure 2 shows the material grading with even and uneven types of porosity distribution. Also,

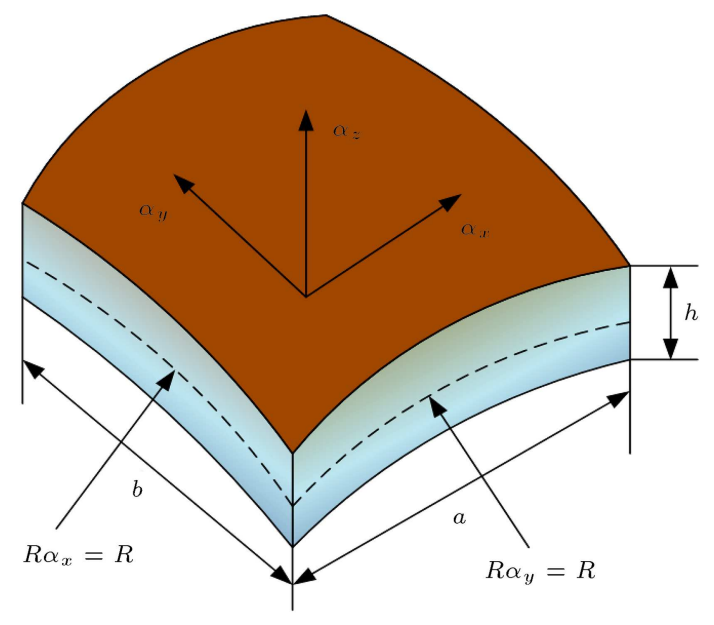

Figure 1. Geometry of Functionally Graded Material (FGM) panel. the relation between volume fraction variation and thickness ratio according to PWL-FGM method is shown in Figure 3.

\subsection{2. $S I G-F G M$}

The ceramic volume fraction in the PWL-FGM method changes rapidly near the bottom and top sides for $n_{z}<1$ and $n_{z}>1$, respectively. Therefore, the smooth variation of material properties is obtained via two power-law functions [1]. Moreover, the individual volume fractions are expressed using the rule of mixture and provided in the following equations (Eqs. (4) and $(5))$. Similarly, the properties of SIG-FGM in association with porosity distribution, i.e., even and uneven types, are calculated using the subsequent steps as given in Eqs. (6) and (7) and Eqs. (8) and (9), respectively [56]:

$$
\begin{aligned}
& P=\left(P^{c}-P^{m}\right)\left[1-0.5\left(1-\frac{2 \alpha_{z}}{h}\right)^{n_{z}}\right]+P^{m} \\
& \text { for } \quad 0 \leq \alpha_{z} \leq h / 2 \\
& P=\left(P^{c}-P^{m}\right)\left[0.5\left(1+\frac{2 \alpha_{z}}{h}\right)^{n_{z}}\right]+P^{m} \\
& \text { for } \quad-h / 2 \leq \alpha_{z} \leq 0
\end{aligned}
$$

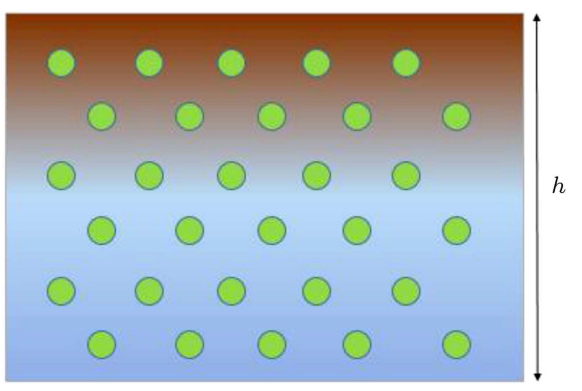

(a) Even

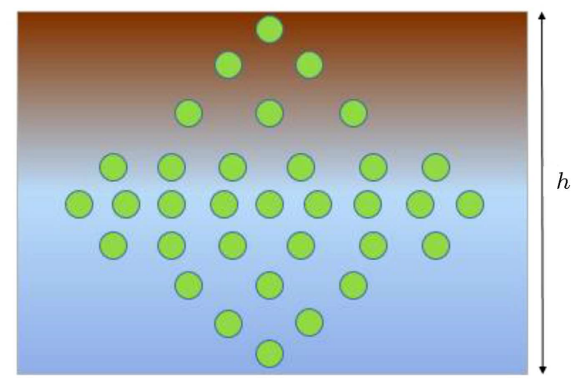

(b) Uneven

Figure 2. Functionally Graded (FG) panel with even and uneven porosity distributions.

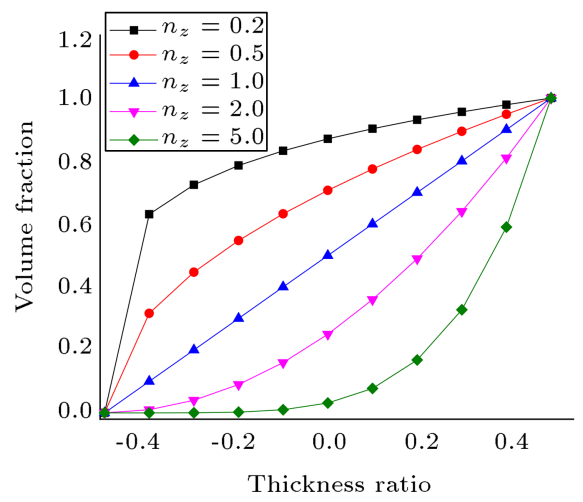

(a) Ceramic volume fraction

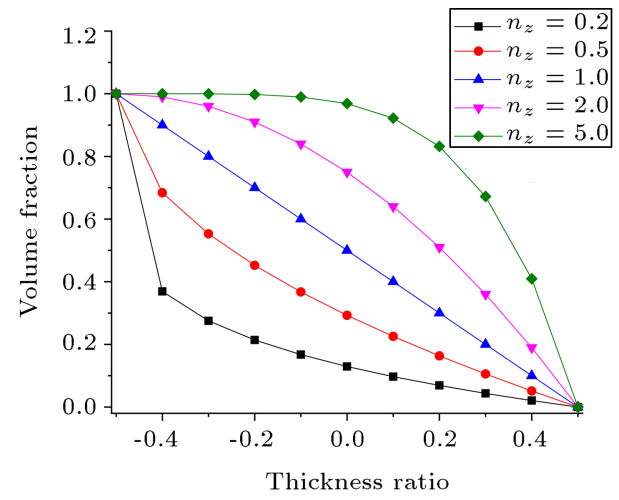

(b) Metal volume fraction

Figure 3. Volume fraction variation in PWL-FGM. 


$$
\begin{aligned}
& P=\left(P^{c}-P^{m}\right)\left[1-0.5\left(1-\frac{2 \alpha_{z}}{h}\right)^{n_{z}}\right]+P^{m} \\
& -0.5 \lambda \times\left(P^{c}+P^{m}\right) \quad \text { for } \quad 0 \leq \alpha_{z} \leq h / 2 \text {, } \\
& P=\left(P^{c}-P^{m}\right)\left[0.5\left(1+\frac{2 \alpha_{z}}{h}\right)^{n_{z}}\right]+P^{m} \\
& -0.5 \lambda \times\left(P^{c}+P^{m}\right) \quad \text { for } \quad-h / 2 \leq \alpha_{z} \leq 0 . \\
& P=\left(P^{c}-P^{m}\right)\left[1-0.5\left(1-\frac{2 \alpha_{z}}{h}\right)^{n_{z}}\right]+P^{m} \\
& -0.5 \lambda \times\left(P^{c}+P^{m}\right)\left(1-\frac{2\left|\alpha_{z}\right|}{h}\right) \\
& P=\left(P^{c}-P^{m}\right)\left[0.5\left(1+\frac{2 \alpha_{z}}{h}\right)^{n_{z}}\right]+P^{m} \\
& -0.5 \lambda \times\left(P^{c}+P^{m}\right)\left(1-\frac{2\left|\alpha_{z}\right|}{h}\right)
\end{aligned}
$$

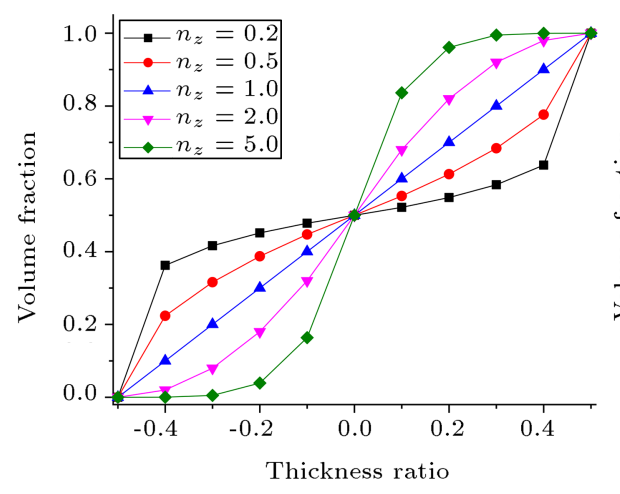

(a) Ceramic volume fraction
The relation between volume fraction and thickness ratio for SIG-FGM is shown in Figure 4 and it is observed that the volume fraction variation of PWLFGM and SIG-FGM is the same at $n_{z}=1$.

\subsection{3. $E X P-F G M$}

The effective material property using EXP-FGM method [1] is described by the following equation given:

$$
P=P^{c} \times e^{-\frac{1}{2} \ln \left(\frac{P^{c}}{P^{m}}\right)\left(1-\frac{2 \alpha_{z}}{h}\right)} .
$$

Now, the effect of even and uneven porosity distributions on the material properties of EXP-FGM is obtained by the following equations:

$$
\begin{aligned}
& P=P^{c} \times e^{\left(-\frac{1}{2} \ln \left(\frac{P^{c}}{P^{m}}\right)\left(1-\frac{2 \alpha_{z}}{h}\right)-0.5 \lambda \times \ln \left(\frac{P^{c}}{P^{m}}\right)\right)}, \\
& P=P^{c} \times e^{\left(-\frac{1}{2} \ln \left(\frac{P^{c}}{P^{m}}\right)\left(1-\frac{2 \alpha_{z}}{h}\right)-0.5 \lambda \times \ln \left(\frac{P^{c}}{P^{m}}\right)\left(1-\frac{2\left|\alpha_{z}\right|}{h}\right)\right) .}
\end{aligned}
$$

The volume fraction distribution by EXP-FGM method in the thickness direction is shown in Figure 5.

\subsection{Displacement field based on HSDT}

The material displacement field model has been expressed in the following lines using the HSDT polynomial [57]:

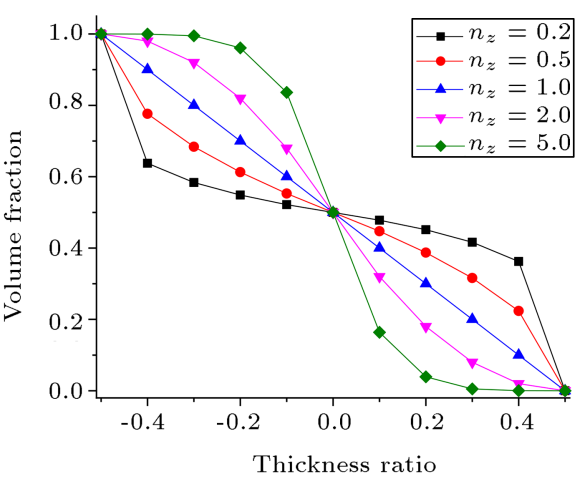

(b) Metal volume fraction

Figure 4. Volume fraction variation in SIG-FGM.

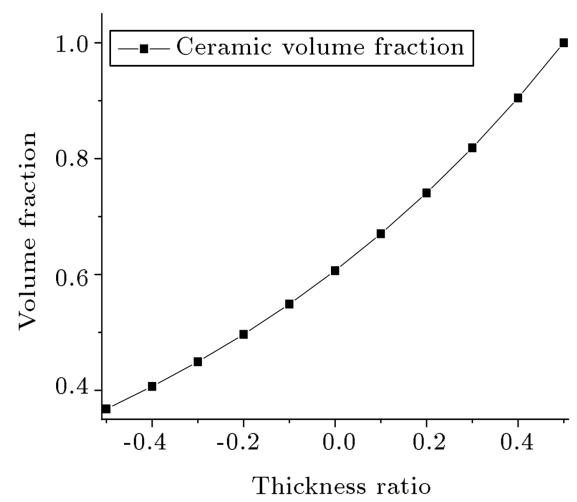

(a) Ceramic volume fraction

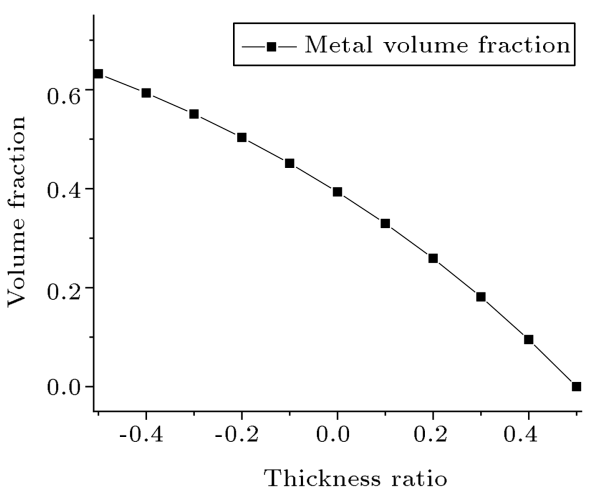

(b) Metal volume fraction

Figure 5. Volume fraction variation in EXP-FGM. 


$$
\begin{aligned}
& \alpha_{x x}\left(\alpha_{x}, \alpha_{y}, \alpha_{z}\right)=\alpha_{x x_{0}}\left(\alpha_{x}, \alpha_{y}\right)+\alpha_{z} \psi_{x}\left(\alpha_{x}, \alpha_{y}\right) \\
& \quad+\alpha_{z}^{2} \alpha_{x x_{0}}^{*}\left(\alpha_{x}, \alpha_{y}\right)+\alpha_{z}^{3} \psi_{x}^{*}\left(\alpha_{x}, \alpha_{y}\right) \\
& \alpha_{y y}\left(\alpha_{x}, \alpha_{y}, \alpha_{z}\right)=\alpha_{y y_{0}}\left(\alpha_{x}, \alpha_{y}\right)+\alpha_{z} \psi_{y}\left(\alpha_{x}, \alpha_{y}\right) \\
& \quad+\alpha_{z}^{2} \alpha_{y y_{0}}^{*}\left(\alpha_{x}, \alpha_{y}\right)+\alpha_{z}^{3} \psi_{y}^{*}\left(\alpha_{x}, \alpha_{y}\right) \\
& \alpha_{z z}\left(\alpha_{x}, \alpha_{y}, \alpha_{z}\right)=\alpha_{z z_{0}}\left(\alpha_{x}, \alpha_{y}\right) .
\end{aligned}
$$

\subsubsection{Strain-displacement relations}

The strain-displacement expression for the FGM structure is represented in Green-Lagrange sense as follows [58]:

$$
\{\varepsilon\}=\varepsilon_{l}=\left\{\begin{array}{c}
\varepsilon_{\alpha_{x} \alpha_{x}} \\
\varepsilon_{\alpha_{y} \alpha_{y}} \\
\gamma_{\alpha_{x} \alpha_{y}} \\
\gamma_{\alpha_{x} \alpha_{z}} \\
\gamma_{\alpha_{y} \alpha_{z}}
\end{array}\right\}=\left\{\begin{array}{c}
\overline{\alpha_{x x}}, \alpha_{x} \\
\overline{\alpha_{y y}}, \alpha_{y} \\
\overline{\alpha_{x x}}, \alpha_{y}+\overline{\alpha_{y y}}, \alpha_{x} \\
\overline{\alpha_{x x}}, \alpha_{z}+\overline{\alpha_{z z}}, \alpha_{x} \\
\overline{\alpha_{y y}}, \alpha_{z}+\overline{\alpha_{z z}}, \alpha_{y}
\end{array}\right\},
$$

where:

$$
\begin{aligned}
& \overline{\alpha_{x x}, \alpha_{x}}=\frac{\partial \alpha_{x x}}{\partial \alpha_{x}}+\frac{\alpha_{z z}}{R_{\alpha_{x}}} ; \quad \overline{\alpha_{x x}, \alpha_{y}}=\frac{\partial \alpha_{x x}}{\partial \alpha_{y}} ; \\
& {\overline{\alpha_{x x}, \alpha_{z}}}=\frac{\partial \alpha_{x x}}{\partial \alpha_{z}} ; \quad{\overline{\alpha_{y y}}}_{\alpha_{x}}=\frac{\partial \alpha_{y y}}{\partial \alpha_{x}} ; \\
& {\overline{\alpha_{y y}, \alpha_{y}}}=\frac{\partial \alpha_{y y}}{\partial \alpha_{y}}+\frac{\alpha_{z z}}{R_{\alpha_{y}}} ; \quad{\overline{\alpha_{y y}, \alpha_{z}}}=\frac{\partial \alpha_{y y}}{\partial \alpha_{z}} ; \\
& {\bar{\alpha} z z, \alpha_{x}}=\frac{\partial \alpha_{z z}}{\partial \alpha_{x}}-\frac{\alpha_{x x}}{R_{\alpha_{x}}} ; \quad \overline{\alpha_{z z}, \alpha_{y}}=\frac{\partial \alpha_{z z}}{\partial \alpha_{y}}-\frac{\alpha_{y y}}{R_{\alpha_{y}}} .
\end{aligned}
$$

Now, the linear strain tensor is:

$$
\begin{aligned}
\left\{\varepsilon_{l}\right\}= & \left\{\begin{array}{c}
\varepsilon_{\alpha_{x}}^{0} \\
\varepsilon_{\alpha_{y}}^{0} \\
\varepsilon_{\alpha_{x} \alpha_{y}}^{0} \\
\varepsilon_{\alpha_{x} \alpha_{z}}^{0} \\
\varepsilon_{\alpha_{y} \alpha_{z}}^{0}
\end{array}\right\}+\alpha_{z}\left\{\begin{array}{c}
k_{\alpha_{x}}^{1} \\
k_{\alpha_{y}}^{1} \\
k_{\alpha_{x} \alpha_{y}}^{1} \\
k_{\alpha_{x} \alpha_{z}}^{1} \\
k_{\alpha_{y} \alpha_{z}}^{1}
\end{array}\right\}+\alpha_{z}^{2}\left\{\begin{array}{c}
k_{\alpha_{x}}^{2} \\
k_{\alpha_{y}}^{2} \\
k_{\alpha_{x} \alpha_{y}}^{2} \\
k_{\alpha_{x} \alpha_{z}}^{2} \\
k_{\alpha_{y} \alpha_{z}}^{2}
\end{array}\right\} \\
& +\alpha_{z}^{3}\left\{\begin{array}{c}
k_{\alpha_{x}}^{3} \\
k_{\alpha_{y}}^{3} \\
k_{\alpha_{x} \alpha_{y}}^{3} \\
k_{\alpha_{x} \alpha_{z}}^{3} \\
k_{\alpha_{y} \alpha_{z}}^{3}
\end{array}\right\},
\end{aligned}
$$

or:

$$
\left\{\varepsilon_{l}\right\}=\left[T_{l}\right]\left\{\overline{\varepsilon_{l}}\right\}=\left\{\varepsilon^{0}\right\}+\alpha_{z}\left\{k^{1}\right\}+\alpha_{z}^{2}\left\{k^{2}\right\}+\alpha_{z}^{3}\left\{k^{3}\right\} .
$$

\subsubsection{FE formulation}

For the proposed mathematical modeling, a nine-noded isoparametric quadrilateral Lagrangian element with nine Degrees Of Freedom (DOF) per node is used for discretization. The FE presentation [59] of the midplane displacement vector using the available shape functions $[N]$ is provided as follows:

$$
\left\{\delta_{0}\right\}=\sum_{i=1}^{9}[N]\left\{\delta_{0_{i}}\right\}
$$

where:

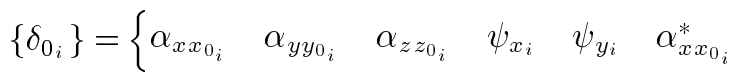

$$
\begin{aligned}
& \left.\alpha_{y y_{0_{i}}}^{*} \quad \psi_{x_{i}}^{*} \quad \psi_{y_{i}}^{*}\right\}^{T}
\end{aligned}
$$

Now, the mid-plane strain term is given below:

$$
\left\{\overline{\varepsilon_{l}}\right\}=[B]\left\{\delta_{0_{i}}\right\} \text {. }
$$

\subsubsection{Stress-strain relation}

The generic form of the constitutive relations [57] for the FGM structural component is expressed as follows:

$\{\sigma\}=\left\{\begin{array}{l}\sigma_{\alpha_{x} \alpha_{x}} \\ \sigma_{\alpha_{y} \alpha_{y}} \\ \tau_{\alpha_{x} \alpha_{y}} \\ \tau_{\alpha_{x} \alpha_{z}} \\ \tau_{\alpha_{y} \alpha_{z}}\end{array}\right\}$

$$
\begin{aligned}
& =\left[\begin{array}{ccccc}
\frac{E}{1-\mu^{2}} & \frac{E \times \mu}{1-\mu^{2}} & 0 & 0 & 0 \\
\frac{E \times \mu}{1-\mu^{2}} & \frac{E}{1-\mu^{2}} & 0 & 0 & 0 \\
0 & 0 & \frac{E}{2(1+\mu)} & 0 & 0 \\
0 & 0 & 0 & \frac{E}{2(1+\mu)} & 0 \\
0 & 0 & 0 & 0 & \frac{E}{2(1+\mu)}
\end{array}\right]\left\{\begin{array}{c}
\varepsilon_{\alpha_{x} \alpha_{x}} \\
\varepsilon_{\alpha_{y} \alpha_{y}} \\
\gamma_{\alpha_{x} \alpha_{y}} \\
\gamma_{\alpha_{x} \alpha_{z}} \\
\gamma_{\alpha_{y} \alpha_{z}}
\end{array}\right\} \\
& =[\bar{Q}]\{\varepsilon\} .
\end{aligned}
$$

Now, the total strain energy of the FG structure is expressed as follows:

$$
U=0.5 \times \int_{v}\{\varepsilon\}^{T}\{\sigma\} d V .
$$

Further, the energy functional can be rewritten by utilizing the corresponding stress and strain terms in Eq. (20) and conceded to the following form:

$$
U=0.5 \times \int_{A}\left(\left\{\overline{\varepsilon_{l}}\right\}^{T}[D]\left\{\overline{\varepsilon_{l}}\right\}\right) d A,
$$

where:

$$
[D]=\int_{-h / 2}^{h / 2}\left[T_{l}\right]^{T}[Q]\left[T_{l}\right] d \alpha_{z} .
$$

Similarly, the work done because of the externally applied mechanical load $(q)$ is expressed as follows:

$$
W=\int_{A}\left\{\delta_{0}\right\}^{T} q d A
$$

or:

$$
W=\left\{\delta_{0}\right\}^{T}\{F\} .
$$

Additionally, the analysis has also been adopted for 
different types of load intensities (uniformly distributed load, step load, point load, etc.) as per the requirement.

\subsubsection{Governing equations}

The static deflection values of the graded structure are obtained through the variational form of the total energy functional and solved to obtain the deflection parameters. The corresponding final form of the structural equilibrium equation is presented in the following:

$$
\delta \Pi=\delta(U-W)=0 .
$$

The above equation has been modified into the matrix form using total stiffness as well as force and displacement vectors in the following equation:

$$
[K]\left\{\delta_{0}\right\}=\{F\} .
$$

Finally, the deflection responses can be obtained by solving Eq. (25).

\subsection{Simulation model of FG structure ( ANSYS and APDL codes)}

A simulation model for the unidirectional graded plate has been developed in the ANSYS platform using the batch input technique (ANSYS parametric design language, APDL) for the validation purpose. The panel model has utilized the SHELL281 element (available in ANSYS element library) with six Degrees Of Freedom (DOF) at each node. In general, ANSYS adopted the FSDT type of displacement kinematics for modeling the structural components. The static bending results are obtained in the ANSYS platform for different kinds of FG structures. The detailed procedure for the development of FG structure, modeling, and analysis is elaborated in three major sub-steps as follows:

Step 1: Preprocessing. In the first step, necessary input data relevant to the geometry (length ' $a$ ' and width ' $b$ ' as well as the total thickness, ' $h$ ') are given to generate FG plate model. Additionally, the finite number of layers is defined in this step to obtain smooth grading through the thickness $(\leq 250)$. The required material properties have also been included, i.e., the metal and ceramic as per the defined relations including the grading pattern. The plate model has been discretized using SHELL281 element, as defined earlier;

Step 2: Solution. The required end boundaries are implemented in this step to avoid the rigid body motion and the corresponding loading type (in this analysis, uniformly distributed transverse load adopted);

Step 3: Postprocessing. Finally, the static deflection responses of the FG plate model are obtained in the pictorial form and the central deflection values are noted down for the validation purpose. Also, a flowchart is presented in Figure 6 to show the modeling and solution steps through the simulation tool. The given process is generalized in nature, i.e., can be adopted to compute all different kinds of unknowns (number of element, solution type, deflections, and stresses). However, the present analysis is only applied to predict the deflection values.

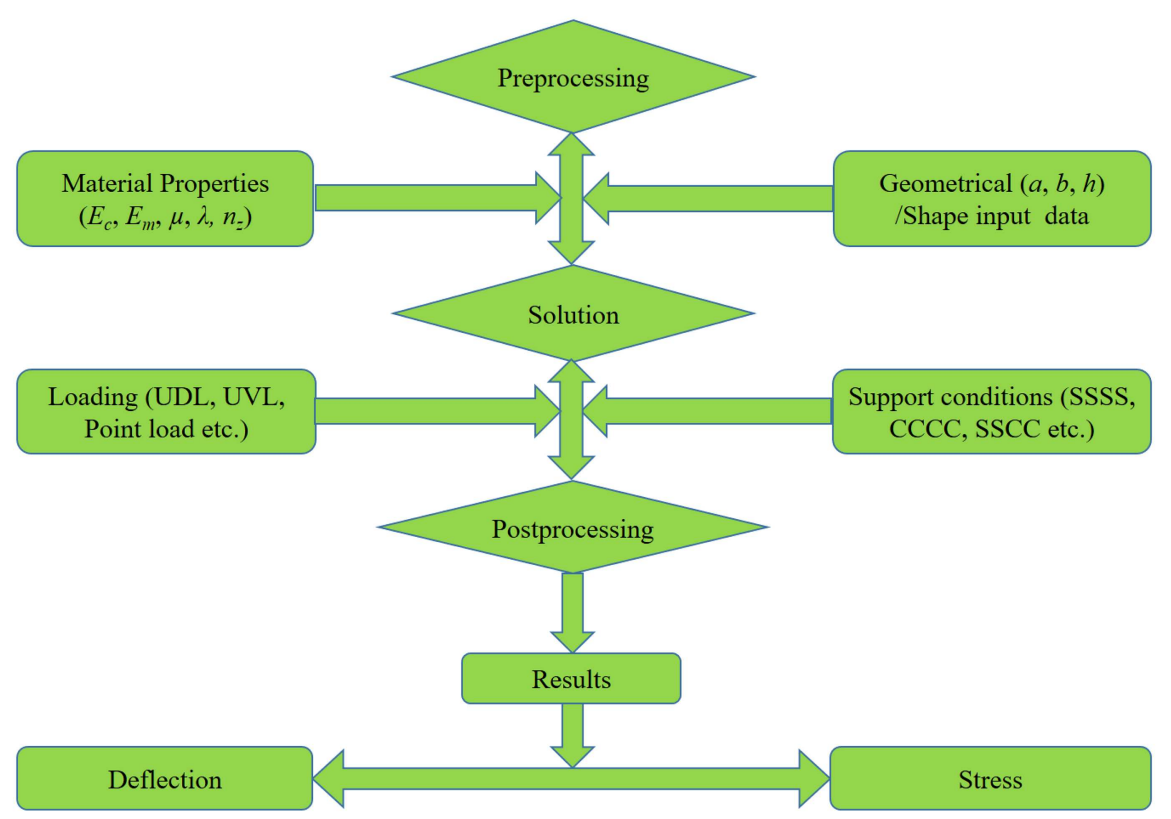

Figure 6. Flowchart presentation of Functionally Graded Material (FGM) simulation modeling steps. 
Table 1. Material properties.

\begin{tabular}{clcc}
\hline \multirow{2}{*}{ Material } & & \multicolumn{2}{c}{ Properties } \\
\cline { 3 - 4 } & & Modulus of elasticity $(\boldsymbol{E})$ in GPa & Poisson's ratio $(\boldsymbol{\mu})$ \\
\hline \multirow{2}{*}{ Ceramic } & Alumina $\left(\mathrm{Al}_{2} \mathrm{O}_{3}\right)$ & 380 & 0.3 \\
& Zirconia $\left(\mathrm{ZrO}_{2}\right)$ & 151 & 0.3 \\
& & & 0.3262 \\
\multirow{2}{*}{ Metal } & Stainless Steel (SUS304) & 201.04 & 0.3 \\
& Aluminium (Al) & 70 & \\
\hline
\end{tabular}

\section{Results and discussions}

Following a successful development of higher-order finite element formulation, an in-house customized computer code has been developed for computational purposes. The convergence behavior of the FE solution has been verified as a priori and extended for the comparison analysis. Also, the static bending and stress results of the graded structure have been evaluated computationally for different design parameters, i.e., thickness ratio $(S)$, aspect ratio $(O)$, curvature ratio $(R / h)$, power-law exponent $\left(n_{z}\right)$, porosity index $(\lambda)$, geometry, and boundary conditions. The necessary elastic properties of the FG material constituents are listed in Table 1.

\subsection{Convergence and validation for bending analysis}

Now, to establish the currently proposed higher-order FE model, few examples similar to the ones in the Reference section are studied in this subsection. In general, the convergence and validations are required to verify the correctness of the present numerical solution. Therefore, the convergence of all three types of FG structures (PWL-FG, SIG-FG, and EXP-FG) is obtained for the $\mathrm{Al}_{2} \mathrm{O}_{3} / \mathrm{Al}$ SSSS (all sides simply supported) FG plate, as shown in Figure 7 . From

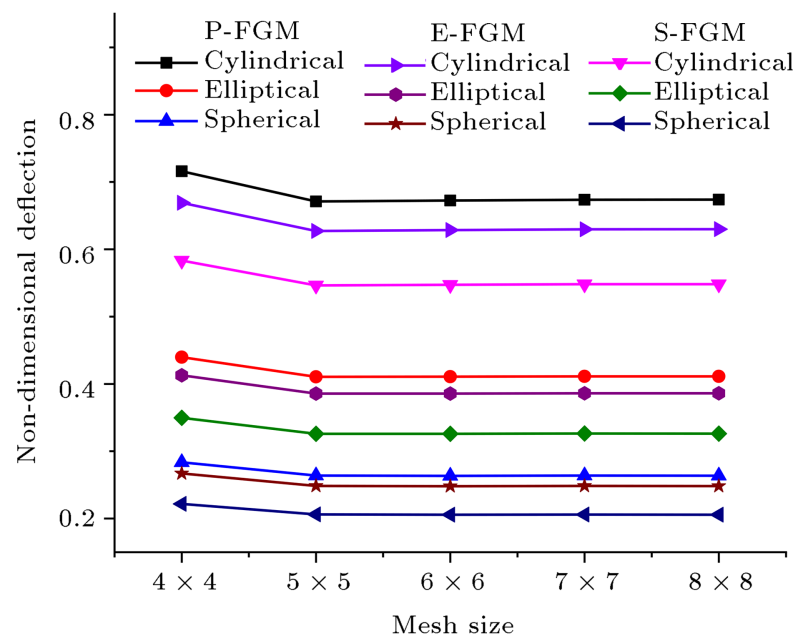

Figure 7. Convergence of SSSS square Functionally Graded Material (FGM) plate for deflection parameter (non-dimensional). the given graph, it can be concluded that a mesh $(6 \times 6)$ is sufficient to evaluate the final output (bending deflection) without deviating from the expected line. The geometrical parameters are chosen similar to the reference, i.e., $a=b=1 \mathrm{~m}, h=a / 10$, and $n_{z}=$ 2. The non-dimensional form of the deflection $[\bar{w}=$ $10 w E^{c} h^{3} /\left(q a^{4}\right)$, where $w$ is the actual deflection, $E_{c}$ is ceramic modulus, and load intensity $q=1 \mathrm{~N} / \mathrm{m}^{2}$ ], is utilized for the convergence and validation of PWLFG structure including the new results, if not stated otherwise.

Further, the non-dimensional deflection responses for the validation study of all three types of FG structure are presented in Figures 8, 9, and 10, showing good agreement with the earlier published deflection values. The verification has been completed for different material constituents according to the available grading patterns, i.e., $\mathrm{Al}_{2} \mathrm{O}_{3} / \mathrm{Al}$ for PWL-FGM [4] while $\mathrm{ZrO}_{2} / \mathrm{Al}$ properties [7] for another two cases (SIG-FGM and EXP-FGM). Similarly, the responses are computed for the simply-supported structural plate including the given geometrical dimension $(a=b=1$, $h=a / 10)$ with different values of the power-law exponent. Also, SIG and EXP types of FG structures are validated for the simply-supported plate with different values of aspect ratios and geometrical data as $b=1 \mathrm{~m}$, $h=0.02 \mathrm{~m}$, and $n_{z}=1$. The non-dimensional form used here is $\bar{w}=100 w E^{m} h^{3} /\left(\left(1-\mu^{2}\right) \times q a^{4}\right)$.

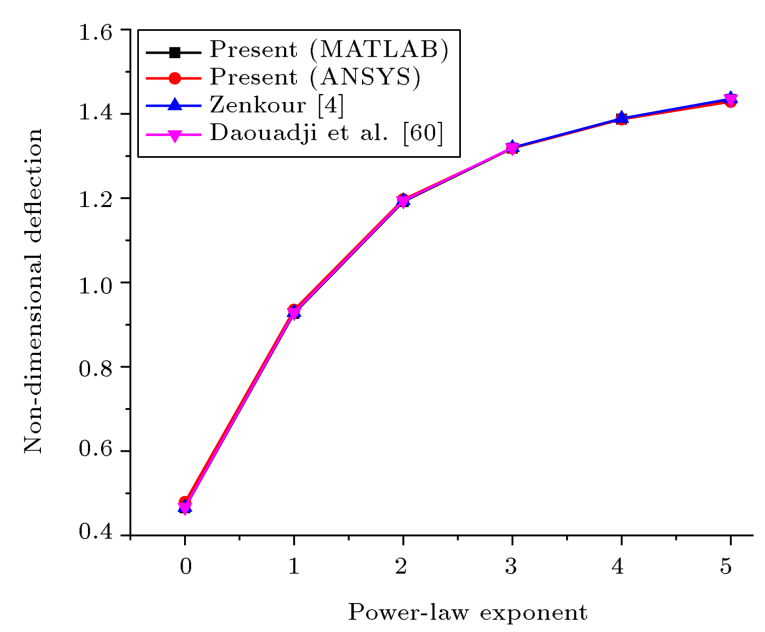

Figure 8. Deflection parameter (non-dimensional) of PWL-FGM. 


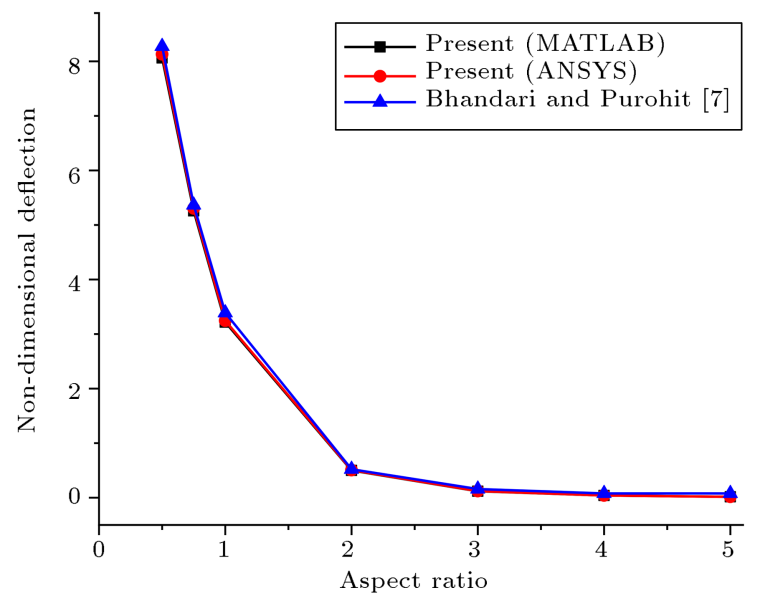

Figure 9. Deflection parameter (non-dimensional) of SIG-FGM.

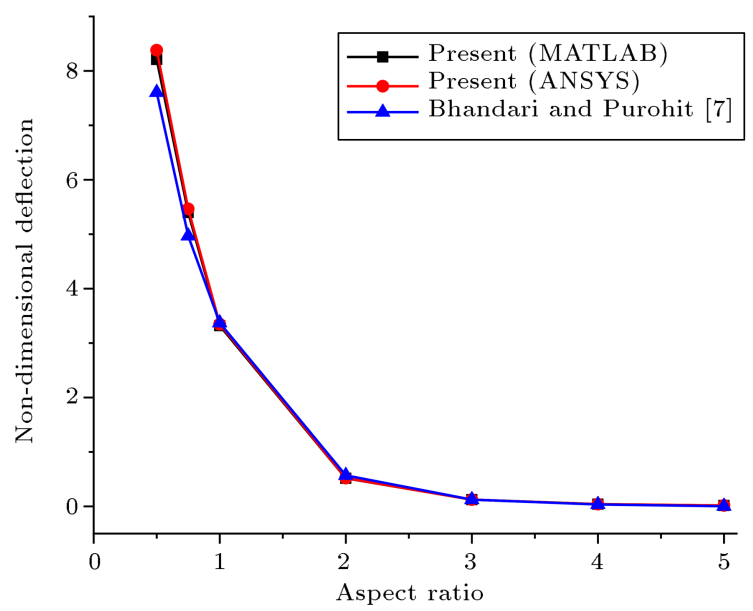

Figure 10. Deflection parameter (non-dimensional) of EXP-FGM.

\subsection{Validation of stress values}

Similar to the deflection parameter, the normal stress values of the variable graded structure, i.e., PWLFGM, SIG-FGM, and EXP-FGM, are computed using the current model and then, are compared with the published data. Figure 11 shows a comparison of the normal stress data of the present and the reference. The responses are evaluated using the similar grading pattern (PWL), material properties $\left(\mathrm{Al}_{2} \mathrm{O}_{3} / \mathrm{Al}\right)$, end boundary condition (SSSS), and the power-law exponents $\left(n_{z}=0,1,2,3,5,10, \infty\right)$ of the reference [60]. The non-dimensional form of the stress is presented the same as the source, i.e., $\overline{\sigma_{x}}=\sigma_{x} \times h / a \times q$. Further, the validation of SIG and EXP types of FG structures is also done for twelve values of aspect ratio $(O=0.1,0.25,0.5,0.75,1,2,3,4,5,6,7,8)$, material properties $\left(\mathrm{ZrO}_{2} / \mathrm{Al}\right)$, and other relevant input parameters (SSSS) similar to the reference [7] and plotted in Figures 12 and 13, respectively. The nondimensional stress values $\left(\overline{\sigma_{x}}=\sigma_{x} \times h^{2} / a^{2} \times q\right)$ are obtained using the given formulae [7].

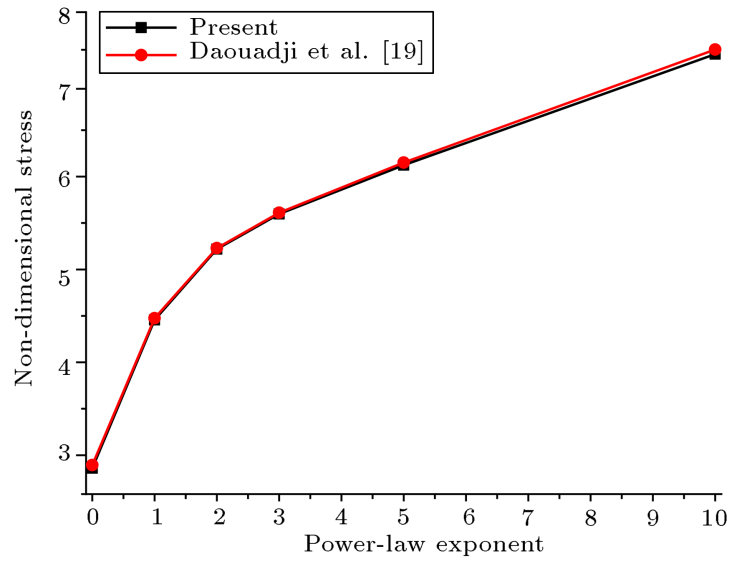

Figure 11. Non-dimensional stress of PWL-FGM $(a=b=0.1, h=0.01)$.

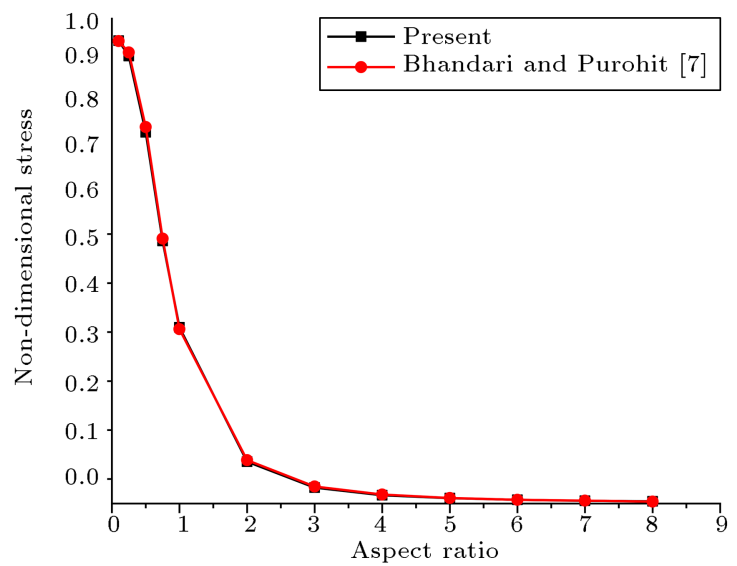

Figure 12. Non-dimensional stress of SIG-FGM $(b=1$, $h=0.02)$.

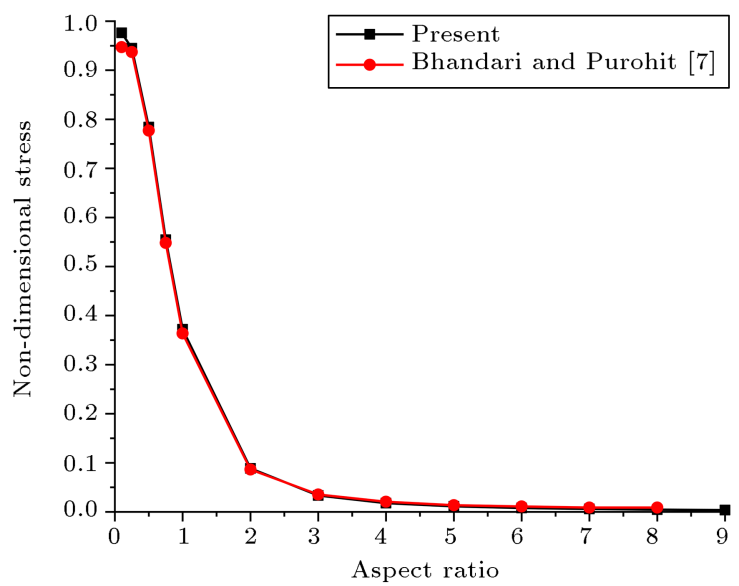

Figure 13. Non-dimensional stress of EXP-FGM $(b=1$, $h=0.02)$.

\subsection{Numerical examples}

After the successful examination and establishment of the present numerical model (element sensitivity and comparison test), the static deflection characteristics of each kind of FG structure including the variety of porosity distribution (even and uneven) are investi- 
gated. Further, new sets of numerical examples are solved for different porosity index values in conjunction with various influencing geometrical parameters (aspect ratio, thickness ratio, power-law exponent, curvature ratio, boundary condition, and geometry). The new examples are solved using the properties of Alumina $\left(\mathrm{Al}_{2} \mathrm{O}_{3}\right)$ and Aluminium $(\mathrm{Al})$ as the ceramic and metal constituents of the FG structure, respectively. The details of properties for each constituent are provided in Table 1.

Now, the influence of the aspect ratio on the deflection (non-dimensional) values of SSSS FG plate is determined for all three kinds of FG structure, as given in Table 2. Based on the results, the nondimensional deflection values are lowered down with an increase in the aspect ratio. This occurs because an increase in aspect ratio or a reduction in the width of the structure causes an increment in the stiffness and, therefore, the deflection of the FG structure is reduced. Also, the rise in porosity causes an increment in the deflection values. Hence, it can be concluded that the overall FG stiffness follows the decreasing slope with an increase in porosity. Further, the density of pores in the uneven type of porosity distribution pattern is higher in the central region of the thickness and it reduces linearly towards the top and bottom surfaces. Therefore, the uneven porosity distribution shows higher strength than the even counterpart with respect to the higher values of the porosity index.

Also, the effects of the thickness ratio values on the FG plate structure are examined and shown in Table 3 for all kinds of grading structure. The result indicates that increase in thickness ratio (reduction in thickness) causes a reduction in the static deflection data of the structure for all the values of porosity indices. This is because the reduction in thickness

Table 2. Effect of aspect ratio on the deflection (non-dimensional) of the SSSS Functionally Graded Material (FGM) plate $\left(a=1, h=a / 100, n_{z}=2\right)$.

\begin{tabular}{|c|c|c|c|c|c|c|c|c|c|}
\hline \multirow{3}{*}{$\begin{array}{c}\text { Type of } \\
\text { FGM }\end{array}$} & \multirow{3}{*}{$\begin{array}{c}\text { Aspect } \\
\text { ratio } \\
(O)\end{array}$} & \multicolumn{8}{|c|}{ Porosity index $(\lambda)$ and distribution } \\
\hline & & \multicolumn{4}{|c|}{ Even } & \multicolumn{4}{|c|}{ Uneven } \\
\hline & & 0 & 0.1 & 0.2 & 0.3 & $\mathbf{0}$ & 0.1 & 0.2 & 0.3 \\
\hline \multirow{3}{*}{ PWL-FGM } & 0.5 & 2.8111 & 3.5087 & 4.7970 & 8.1708 & 2.8111 & 2.9898 & 3.2045 & 3.4696 \\
\hline & 1 & 1.1312 & 1.4119 & 1.9303 & 3.288 & 1.1312 & 1.2031 & 1.2895 & 1.3962 \\
\hline & 2 & 0.1762 & 0.2199 & 0.3005 & 0.5116 & 0.1762 & 0.1874 & 0.2008 & 0.2175 \\
\hline \multirow{3}{*}{ SIG-FGM } & 0.5 & 2.4526 & 2.9523 & 3.7596 & 5.3211 & 2.4526 & 2.5830 & 2.7339 & 2.9113 \\
\hline & 1 & 0.9869 & 1.1880 & 1.5129 & 2.1412 & 0.9869 & 1.0394 & 1.1001 & 1.1715 \\
\hline & 2 & 0.1537 & 0.1849 & 0.2355 & 0.3332 & 0.1537 & 0.1618 & 0.1713 & 0.1824 \\
\hline \multirow{3}{*}{ EXP-FGM } & 0.5 & 2.6010 & 2.8306 & 3.0804 & 3.3523 & 2.6010 & 2.6651 & 2.7301 & 2.7961 \\
\hline & 1 & 1.0466 & 1.1390 & 1.2395 & 1.3490 & 1.0466 & 1.0724 & 1.0986 & 1.1251 \\
\hline & 2 & 0.1630 & 0.1774 & 0.1931 & 0.2101 & 0.1630 & 0.1670 & 0.1711 & 0.1753 \\
\hline
\end{tabular}

Table 3. Effect of thickness ratio on the deflection (non-dimensional) of the SSSS Functionally Graded Material (FGM) plate $\left(a=b=1, h=a / S, n_{z}=2\right)$.

\begin{tabular}{|c|c|c|c|c|c|c|c|c|c|}
\hline \multirow{3}{*}{$\begin{array}{c}\text { Type of } \\
\text { FGM }\end{array}$} & \multirow{3}{*}{$\begin{array}{c}\text { Thickness } \\
\text { ratio } \\
(S)\end{array}$} & \multicolumn{8}{|c|}{ Porosity index $(\lambda)$ and distribution } \\
\hline & & \multicolumn{4}{|c|}{ Even } & \multicolumn{4}{|c|}{ Uneven } \\
\hline & & $\mathbf{0}$ & 0.1 & 0.2 & 0.3 & $\mathbf{0}$ & 0.1 & 0.2 & 0.3 \\
\hline \multirow{3}{*}{ PWL-FGM } & 10 & 1.2110 & 1.5051 & 2.0426 & 3.4305 & 1.2110 & 1.2899 & 1.3850 & 1.5029 \\
\hline & 50 & 1.1350 & 1.4163 & 1.9355 & 3.2944 & 1.1350 & 1.2072 & 1.2940 & 1.4012 \\
\hline & 100 & 1.1312 & 1.4119 & 1.9303 & 3.2880 & 1.1312 & 1.2031 & 1.2895 & 1.3962 \\
\hline \multirow{3}{*}{ SIG-FGM } & 10 & 1.0479 & 1.2565 & 1.5909 & 2.2331 & 1.0479 & 1.1041 & 1.1693 & 1.2458 \\
\hline & 50 & 0.9898 & 1.1912 & 1.5165 & 2.1454 & 0.9898 & 1.0424 & 1.1034 & 1.1750 \\
\hline & 100 & 0.9869 & 1.1880 & 1.5129 & 2.1412 & 0.9869 & 1.0394 & 1.1001 & 1.1715 \\
\hline \multirow{3}{*}{ EXP-FGM } & 10 & 1.1210 & 1.2199 & 1.3276 & 1.4448 & 1.1210 & 1.1501 & 1.1798 & 1.2100 \\
\hline & 50 & 1.0502 & 1.1429 & 1.2438 & 1.3535 & 1.0502 & 1.0761 & 1.1025 & 1.1292 \\
\hline & 100 & 1.0466 & 1.1390 & 1.2395 & 1.3490 & 1.0466 & 1.0724 & 1.0986 & 1.1251 \\
\hline
\end{tabular}


of the plate structure reduces the stiffness, which, in turn, increases the deflection value. However, the tabular values follow a decreasing slope due to the nondimensional form.

In addition, the effect of curvature ratio on the non-dimensional deflection of the FG hyperboloid panel is presented in Table 4, indicating upon an increase in the radius of curvature or curvature ratio of the panel, the structure becomes stiffer, which results in the reduction of deflection values. Further, the effect of CCCC (clamped), SCSC (two sides simply supported and two sides clamped), and CFCF (two sides clamped and two sides free) end conditions on the bending responses of the FG structure is presented in Table 5 . In general, the stiffness of any structure increases when the end constraint of the panel edges increases. For CCCC condition, all the movements are restricted, whereas under CFCF condition, no movements are constrained at two opposite edges. Hence, the plate deflection values for the clamped structure are minimum, and maximum deflection is observed in the case CFCF end boundary conditions.

Similarly, the static deflection responses of the FG structure due to the variation of geometrical shape $(R / a=10)$ are shown in Table 6 . The results indicate the maximum deflection observed for the cylindrical panel structure as it is softer than the spherical and elliptical panel. Also, the spherical panel has the highest stiffness among all other panels and, therefore, it shows minimum deflection.

Table 4. Effect of curvature ratio on the deflection (non-dimensional) of the SSSS Functionally Graded Material (FGM) hyperboloid panel $\left(a=b=1, h=a / 100, n_{z}=2\right)$.

\begin{tabular}{|c|c|c|c|c|c|c|c|c|c|}
\hline \multirow{3}{*}{$\begin{array}{c}\text { Type of } \\
\text { FGM }\end{array}$} & \multirow{3}{*}{$\begin{array}{c}\text { Curvature } \\
\text { ratio } \\
(R / h)\end{array}$} & \multicolumn{8}{|c|}{ Porosity index $(\lambda)$ and distribution } \\
\hline & & \multicolumn{4}{|c|}{ Even } & \multicolumn{4}{|c|}{ Uneven } \\
\hline & & $\mathbf{0}$ & 0.1 & 0.2 & 0.3 & $\mathbf{0}$ & 0.1 & 0.2 & 0.3 \\
\hline \multirow{3}{*}{ PWL-FGM } & 100 & 1.2654 & 1.5648 & 2.0991 & 3.3909 & 1.2654 & 1.3467 & 1.4438 & 1.5629 \\
\hline & 300 & 1.1552 & 1.4411 & 1.9678 & 3.3385 & 1.1552 & 1.2286 & 1.3469 & 1.4259 \\
\hline & 500 & 1.1415 & 1.4247 & 1.9476 & 3.3158 & 1.1415 & 1.2140 & 1.3012 & 1.4089 \\
\hline \multirow{3}{*}{ SIG-FGM } & 100 & 1.0833 & 1.2969 & 1.6235 & 2.2205 & 1.0833 & 1.1461 & 1.2127 & 1.2905 \\
\hline & 300 & 1.0070 & 1.2114 & 1.5408 & 2.1751 & 1.0070 & 1.0605 & 1.1225 & 1.1953 \\
\hline & 500 & 0.9958 & 1.1987 & 1.5263 & 2.1595 & 0.9958 & 1.0488 & 1.1101 & 1.1821 \\
\hline \multirow{3}{*}{ EXP-FGM } & 100 & 1.1737 & 1.2773 & 1.3900 & 1.5127 & 1.1737 & 1.2045 & 1.2359 & 1.2676 \\
\hline & 300 & 1.0690 & 1.1634 & 1.2660 & 1.3778 & 1.0690 & 1.0954 & 1.1223 & 1.1495 \\
\hline & 500 & 1.0562 & 1.1494 & 1.2508 & 1.3612 & 1.0562 & 1.0822 & 1.1086 & 1.1354 \\
\hline
\end{tabular}

Table 5. Effect of support conditions on the deflection (non-dimensional) of Functionally Graded Material (FGM) plate $\left(a=b=1, h=a / 100, n_{z}=2\right)$.

\begin{tabular}{|c|c|c|c|c|c|c|c|c|c|}
\hline \multirow{3}{*}{$\begin{array}{c}\text { Type of } \\
\text { FGM }\end{array}$} & \multirow{3}{*}{$\begin{array}{l}\text { Boundary } \\
\text { conditions }\end{array}$} & \multicolumn{8}{|c|}{ Porosity index $(\lambda)$ and distribution } \\
\hline & & \multicolumn{4}{|c|}{ Even } & \multicolumn{4}{|c|}{ Uneven } \\
\hline & & $\mathbf{0}$ & 0.1 & 0.2 & 0.3 & $\mathbf{0}$ & 0.1 & 0.2 & 0.3 \\
\hline \multirow{3}{*}{ PWL-FGM } & $\mathrm{CCCC}$ & 0.3220 & 0.4018 & 0.5490 & 0.9338 & 0.3220 & 0.3425 & 0.3672 & 0.3976 \\
\hline & $\mathrm{SCSC}$ & 0.4969 & 0.6200 & 0.8472 & 1.4416 & 0.4969 & 0.5285 & 0.5665 & 0.6134 \\
\hline & $\mathrm{CFCF}$ & 0.6603 & 0.8239 & 1.1256 & 1.9144 & 0.6603 & 0.7024 & 0.7529 & 0.8154 \\
\hline \multirow{3}{*}{ SIG-FGM } & $\mathrm{CCCC}$ & 0.2808 & 0.3378 & 0.4300 & 0.6081 & 0.2808 & 0.2957 & 0.3130 & 0.3333 \\
\hline & SCSC & 0.4333 & 0.5214 & 0.6637 & 0.9388 & 0.4333 & 0.4563 & 0.4830 & 0.5144 \\
\hline & $\mathrm{CFCF}$ & 0.5757 & 0.6927 & 0.8816 & 1.2467 & 0.5757 & 0.6063 & 0.6418 & 0.6834 \\
\hline \multirow{3}{*}{ EXP-FGM } & $\mathrm{CCCC}$ & 0.2980 & 0.3243 & 0.3529 & 0.3840 & 0.2980 & 0.3053 & 0.3128 & 0.3204 \\
\hline & SCSC & 0.4598 & 0.5003 & 0.5445 & 0.5926 & 0.4598 & 0.4711 & 0.4827 & 0.4944 \\
\hline & $\mathrm{CFCF}$ & 0.6110 & 0.6650 & 0.7237 & 0.7875 & 0.6110 & 0.6262 & 0.6415 & 0.6571 \\
\hline
\end{tabular}


Table 6. Effect of geometry on the deflection (non-dimensional) of the SSSS Functionally Graded Material (FGM) structure $\left(a=b=1, h=0.1, n_{z}=2, R=10\right)$.

\begin{tabular}{|c|c|c|c|c|c|c|c|c|c|}
\hline \multirow{3}{*}{$\begin{array}{c}\text { Type of } \\
\text { FGM }\end{array}$} & \multirow{3}{*}{ Geometry } & \multicolumn{8}{|c|}{ Porosity index $(\lambda)$ and distribution } \\
\hline & & \multicolumn{4}{|c|}{ Even } & \multicolumn{3}{|c|}{ Uneven } & \multirow[b]{2}{*}{0.3} \\
\hline & & $\mathbf{0}$ & 0.1 & 0.2 & 0.3 & $\mathbf{0}$ & 0.1 & 0.2 & \\
\hline \multirow{3}{*}{ PWL-FGM } & Cylindrical & 1.2006 & 1.4909 & 2.0197 & 3.3728 & 1.2006 & 1.279 & 1.3735 & 1.4906 \\
\hline & Spherical & 1.1701 & 1.45 & 1.9557 & 3.2249 & 1.1701 & 1.2468 & 1.3392 & 1.4534 \\
\hline & Elliptical & 1.1875 & 1.4732 & 1.992 & 3.3081 & 1.1875 & 1.2651 & 1.3587 & 1.4746 \\
\hline \multirow{3}{*}{ SIG-FGM } & Cylindrical & 1.0376 & 1.2429 & 1.571 & 2.1966 & 1.0376 & 1.0934 & 1.1579 & 1.2337 \\
\hline & Spherical & 1.008 & 1.2045 & 1.5163 & 2.1023 & 1.008 & 1.0621 & 1.1248 & 1.1983 \\
\hline & Elliptical & 1.0248 & 1.2263 & 1.5473 & 2.1554 & 1.0248 & 1.0799 & 1.1436 & 1.2184 \\
\hline \multirow{3}{*}{ EXP-FGM } & Cylindrical & 1.1116 & 1.2097 & 1.3165 & 1.4327 & 1.1116 & 1.1407 & 1.1703 & 1.2004 \\
\hline & Spherical & 1.0839 & 1.1795 & 1.2837 & 1.397 & 1.0839 & 1.1127 & 1.1419 & 1.1718 \\
\hline & Elliptical & 1.0996 & 1.1967 & 1.3023 & 1.4172 & 1.0996 & 1.1286 & 1.158 & 1.188 \\
\hline
\end{tabular}

Table 7. Effect of power-law exponent, porosity index, and loading (UDL) on the deflection (non-dimensional) of the SSSS Functionally Graded Material (FGM) plate $(a=b=1, h=a / 100)$.

\begin{tabular}{|c|c|c|c|c|c|c|c|c|c|}
\hline \multirow{3}{*}{$\begin{array}{c}\text { Type of } \\
\text { FGM }\end{array}$} & \multirow{3}{*}{$\begin{array}{c}\text { Power-law } \\
\text { exponent } \\
\left(n_{z}\right)\end{array}$} & \multicolumn{8}{|c|}{ Porosity index $(\lambda)$ and distribution } \\
\hline & & \multicolumn{4}{|c|}{ Even } & \multicolumn{4}{|c|}{ Uneven } \\
\hline & & $\mathbf{0}$ & 0.1 & 0.2 & 0.3 & $\mathbf{0}$ & 0.1 & 0.2 & 0.3 \\
\hline \multirow{3}{*}{ PWL-FGM } & 0 & 0.4400 & 0.4677 & 0.4991 & 0.5350 & 0.4400 & 0.4466 & 0.4534 & 0.4605 \\
\hline & 1 & 0.8826 & 1.0259 & 1.2336 & 1.5673 & 0.8826 & 0.9190 & 0.9597 & 1.0056 \\
\hline & 2 & 1.1312 & 1.4119 & 1.9303 & 3.2880 & 1.1312 & 1.2031 & 1.2895 & 1.3962 \\
\hline \multirow{3}{*}{ SIG-FGM } & 0 & 0.7431 & 0.8257 & 0.9289 & 1.0615 & 0.7431 & 0.7622 & 0.7823 & 0.8034 \\
\hline & 1 & 0.8826 & 1.0259 & 1.2336 & 1.5673 & 0.8826 & 0.919 & 0.9597 & 1.0056 \\
\hline & 2 & 0.9869 & 1.188 & 1.5129 & 2.1412 & 0.9869 & 1.0394 & 1.1001 & 1.1715 \\
\hline
\end{tabular}

Further, the effects of power-law exponent on the bending characteristics of different FG structures, i.e., PWL and SIG types, are evaluated for the simplysupported case. The deflection results are presented in Table 7. It is observed from the results that the deflection values are increasing, i.e., the structural stiffness lowers with an increase in the power-law exponent. This is because the metal volume fraction within the graded FG panel increases when power-law exponent increases. This, in turn, lowers the total structural stiffness of the panel and allows the panel to deform high. It would be interesting to note that the deflection results are the same for both kinds of grading (PWL and SIG) for the unity exponent, i.e., $n_{z}=1$.

Bending-induced stress plays an important role in designing any kind of structure/structural components. Now, the effects of different geometrical parameters (aspect ratio, thickness ratio, and geometrical config- uration) on the non-dimensional stress (normal and shear) values have been measured through the present higher-order FE model considering the porosity and the distribution type. The results are obtained for all three kinds of grading pattern (PWL, SIG and EXP) and tabulated in Tables 8-10. The stress data are mainly obtained for the simply-supported $\mathrm{FG}$ $\left(\mathrm{Al}_{2} \mathrm{O}_{3} / \mathrm{Al}\right)$ structure using the individual constituent properties according to Table 1 . Moreover, the powerlaw exponent value for two types of grading, i.e., PWL and SIG, is considered $n_{z}=2$. The non-dimensional form of the stress parameter for grading types is taken as $\overline{\sigma_{x}}=\sigma_{x} \times h / a \times q, \overline{\sigma_{y}}=\sigma_{y} \times h / a \times q$ and $\overline{\tau_{x y}}=$ $\tau_{x y} \times h / a \times q$, where $q$ is uniformly distributed loading of Magnitude $1 \mathrm{~N} / \mathrm{m}^{2}$. The effect of aspect ratio on the stress responses of PWL-FG, SIG-FG, and EXP-FG structure is presented in Table 8. It is observed from the results that the increase in aspect ratio causes a reduction in stress values of the FG structure. Also, 
Table 8. Effect of aspect ratio on the non-dimensional stress responses of simply-supported Functionally Graded Material (FGM) plates $(a=0.1, b=a / O, h=0.01)$.

\begin{tabular}{|c|c|c|c|c|c|c|c|c|c|c|}
\hline \multirow{3}{*}{$\begin{array}{c}\text { Type of } \\
\text { FGM }\end{array}$} & \multirow{3}{*}{$\begin{array}{c}\text { Aspect } \\
\text { ratio } \\
(O)\end{array}$} & \multirow{3}{*}{ Stress } & \multicolumn{8}{|c|}{ Porosity index $(\lambda)$ and distribution } \\
\hline & & & \multicolumn{4}{|c|}{ Even } & \multicolumn{3}{|c|}{ Uneven } & \multirow[b]{2}{*}{0.3} \\
\hline & & & 0 & 0.1 & 0.2 & 0.3 & 0 & 0.1 & 0.2 & \\
\hline \multirow{9}{*}{ PWL-FGM } & \multirow{3}{*}{0.5} & $\overline{\sigma_{x}}$ & 10.9923 & 12.1034 & 14.1082 & 19.2173 & 10.9923 & 11.3542 & 11.7549 & 12.2059 \\
\hline & & $\overline{\sigma_{y}}$ & 5.0375 & 5.5484 & 6.4708 & 8.8256 & 5.0375 & 5.2029 & 5.3855 & 5.5905 \\
\hline & & $\overline{\tau_{x y}}$ & 0.0059 & 0.0064 & 0.0075 & 0.01 & 0.0059 & 0.0061 & 0.0063 & 0.0065 \\
\hline & \multirow{3}{*}{1} & $\overline{\sigma_{x}}$ & 5.2182 & 5.7502 & 6.7095 & 9.1505 & 5.2182 & 5.3915 & 5.5835 & 5.7999 \\
\hline & & $\overline{\sigma_{y}}$ & 5.2157 & 5.7461 & 6.703 & 9.1391 & 5.2157 & 5.3885 & 5.58 & 5.7958 \\
\hline & & $\overline{\tau_{x y}}$ & 0.0119 & 0.013 & 0.0151 & 0.0204 & 0.0119 & 0.0122 & 0.0127 & 0.0132 \\
\hline & \multirow{3}{*}{2} & $\overline{\sigma_{x}}$ & 1.2686 & 1.3984 & 1.6312 & 2.2163 & 1.2686 & 1.3119 & 1.3602 & 1.4148 \\
\hline & & $\overline{\sigma_{y}}$ & 2.7636 & 3.0457 & 3.5511 & 4.8182 & 2.7636 & 2.8585 & 2.9645 & 3.085 \\
\hline & & $\overline{\tau_{x y}}$ & 0.0053 & 0.0059 & 0.0068 & 0.009 & 0.0053 & 0.0055 & 0.0057 & 0.006 \\
\hline \multirow{9}{*}{ SIG-FGM } & \multirow{3}{*}{0.5} & $\overline{\sigma_{x}}$ & 9.7402 & 10.5441 & 11.8531 & 14.4009 & 9.7402 & 10.0457 & 10.3827 & 10.759 \\
\hline & & $\overline{\sigma_{y}}$ & 4.4621 & 4.8318 & 5.4345 & 6.6095 & 4.4621 & 4.6018 & 4.7559 & 4.9277 \\
\hline & & $\overline{\tau_{x y}}$ & 0.0052 & 0.0056 & 0.0063 & 0.0075 & 0.0052 & 0.0053 & 0.0055 & 0.0057 \\
\hline & \multirow{3}{*}{1} & $\overline{\sigma_{x}}$ & 4.6232 & 5.0074 & 5.6327 & 6.8485 & 4.6232 & 4.7691 & 4.9303 & 5.1103 \\
\hline & & $\overline{\sigma_{y}}$ & 4.6217 & 5.0052 & 5.6296 & 6.8446 & 4.6217 & 4.7674 & 4.9281 & 5.1078 \\
\hline & & $\overline{\tau_{x y}}$ & 0.0105 & 0.0113 & 0.0127 & 0.0153 & 0.0105 & 0.0108 & 0.0112 & 0.0116 \\
\hline & \multirow{3}{*}{2} & $\overline{\sigma_{x}}$ & 1.1225 & 1.2155 & 1.3658 & 1.6556 & 1.1225 & 1.1586 & 1.1985 & 1.2433 \\
\hline & & $\overline{\sigma_{y}}$ & 2.4464 & 2.6483 & 2.9746 & 3.6026 & 2.4464 & 2.5253 & 2.6127 & 2.7107 \\
\hline & & $\overline{\tau_{x y}}$ & 0.0047 & 0.0051 & 0.0056 & 0.0067 & 0.0047 & 0.0048 & 0.005 & 0.0052 \\
\hline \multirow{9}{*}{ EXP-FGM } & \multirow{3}{*}{0.5} & $\overline{\sigma_{x}}$ & 10.5777 & 10.5777 & 10.5777 & 10.5777 & 10.5777 & 10.7626 & 10.9476 & 11.1326 \\
\hline & & $\overline{\sigma_{y}}$ & 4.8479 & 4.8479 & 4.8479 & 4.8479 & 4.8479 & 4.9328 & 5.0177 & 5.1026 \\
\hline & & $\overline{\tau_{x y}}$ & 0.0057 & 0.0057 & 0.0057 & 0.0057 & 0.0057 & 0.0058 & 0.0059 & 0.006 \\
\hline & \multirow{3}{*}{1} & $\overline{\sigma_{x}}$ & 5.0194 & 5.0194 & 5.0194 & 5.0194 & 5.0194 & 5.1075 & 5.1956 & 5.2838 \\
\hline & & $\overline{\sigma_{y}}$ & 5.0174 & 5.0174 & 5.0174 & 5.0174 & 5.0174 & 5.1053 & 5.1932 & 5.2811 \\
\hline & & $\overline{\tau_{x y}}$ & 0.0114 & 0.0114 & 0.0114 & 0.0114 & 0.0114 & 0.0116 & 0.0118 & 0.012 \\
\hline & \multirow{3}{*}{2} & $\overline{\sigma_{x}}$ & 1.2192 & 1.2192 & 1.2192 & 1.2192 & 1.2192 & 1.241 & 1.2628 & 1.2845 \\
\hline & & $\overline{\sigma_{y}}$ & 2.6555 & 2.6555 & 2.6555 & 2.6555 & 2.6555 & 2.7028 & 2.7502 & 2.7976 \\
\hline & & $\overline{\tau_{x y}}$ & 0.0051 & 0.0051 & 0.0051 & 0.0051 & 0.0051 & 0.0052 & 0.0053 & 0.0054 \\
\hline
\end{tabular}

the stresses in the PWL-FG structure are higher than those in the SIG-FGM and EXP-FGM for the variable aspect ratio.

Similarly, the effect of thickness ratio on the stress behavior of all three types of FG structures is presented in Table 9. It is clear from the obtained results that with an increase in thickness ratio (reduction in thickness), the results follow a decreasing value progressively, i.e., PWL $>$ SIG $>$ EXP.

Also, the effect of different types of geometry (cylindrical, spherical, and elliptical) on the stress responses of the FG structure is obtained and shown in Table 10 considering $R / a=10$. From the results, it is observed that the higher stress values are obtained for 
Table 9. Effect of thickness ratio on the non-dimensional stress responses of simply-supported Functionally Graded Material (FGM) plates $(a=0.1, h=a / S, b=0.04)$.

\begin{tabular}{|c|c|c|c|c|c|c|c|c|c|c|}
\hline \multirow{3}{*}{$\begin{array}{c}\text { Type of } \\
\text { FGM }\end{array}$} & \multirow{3}{*}{$\begin{array}{c}\text { Thickness } \\
\text { ratio } \\
(S)\end{array}$} & \multirow{3}{*}{ Stress } & \multicolumn{8}{|c|}{ Porosity index $(\lambda)$ and distribution } \\
\hline & & & \multicolumn{4}{|c|}{ Even } & \multicolumn{4}{|c|}{ Uneven } \\
\hline & & & $\mathbf{0}$ & 0.1 & 0.2 & 0.3 & 0 & 0.1 & 0.2 & 0.3 \\
\hline \multirow{9}{*}{ PWL-FGM } & \multirow{3}{*}{5} & $\overline{\sigma_{x}}$ & 0.3988 & 0.4421 & 0.5175 & 0.6943 & 0.3988 & 0.4152 & 0.434 & 0.4561 \\
\hline & & $\overline{\sigma_{y}}$ & 1.0415 & 1.1545 & 1.3504 & 1.8035 & 1.0415 & 1.0855 & 1.1362 & 1.1962 \\
\hline & & $\overline{\tau_{x y}}$ & 0.0021 & 0.0024 & 0.0028 & 0.0036 & 0.0021 & 0.0023 & 0.0024 & 0.0025 \\
\hline & \multirow{3}{*}{10} & $\overline{\sigma_{x}}$ & 0.7534 & 0.8306 & 0.9685 & 1.3114 & 0.7534 & 0.7797 & 0.8091 & 0.8425 \\
\hline & & $\overline{\sigma_{y}}$ & 1.9734 & 2.1761 & 2.5376 & 3.4345 & 1.9734 & 2.043 & 2.121 & 2.2102 \\
\hline & & $\overline{\tau_{x y}}$ & 0.0036 & 0.0039 & 0.0045 & 0.006 & 0.0036 & 0.0037 & 0.0039 & 0.004 \\
\hline & \multirow{3}{*}{20} & $\overline{\sigma_{x}}$ & 1.4748 & 1.6228 & 1.8892 & 2.5655 & 1.4748 & 1.5235 & 1.5774 & 1.638 \\
\hline & & $\overline{\sigma_{y}}$ & 3.8902 & 4.283 & 4.9907 & 6.7873 & 3.8902 & 4.0192 & 4.1622 & 4.3235 \\
\hline & & $\overline{\tau_{x y}}$ & 0.0064 & 0.007 & 0.008 & 0.0106 & 0.0064 & 0.0066 & 0.0068 & 0.0071 \\
\hline \multirow{9}{*}{ SIG-FGM } & \multirow{3}{*}{5} & $\overline{\sigma_{x}}$ & 0.3509 & 0.3804 & 0.4267 & 0.5114 & 0.3509 & 0.3638 & 0.3782 & 0.3946 \\
\hline & & $\overline{\sigma_{y}}$ & 0.9163 & 0.9929 & 1.1123 & 1.3288 & 0.9163 & 0.9504 & 0.9887 & 1.0325 \\
\hline & & $\overline{\tau_{x y}}$ & 0.0019 & 0.002 & 0.0022 & 0.0026 & 0.0019 & 0.002 & 0.002 & 0.0022 \\
\hline & \multirow{3}{*}{10} & $\overline{\sigma_{x}}$ & 0.6661 & 0.721 & 0.8094 & 0.9787 & 0.6661 & 0.6878 & 0.7119 & 0.7389 \\
\hline & & $\overline{\sigma_{y}}$ & 1.7456 & 1.8896 & 2.1213 & 2.5638 & 1.7456 & 1.8029 & 1.8665 & 1.938 \\
\hline & & $\overline{\tau_{x y}}$ & 0.0031 & 0.0034 & 0.0038 & 0.0045 & 0.0031 & 0.0033 & 0.0034 & 0.0035 \\
\hline & \multirow{3}{*}{20} & $\overline{\sigma_{x}}$ & 1.3055 & 1.4122 & 1.5857 & 1.9224 & 1.3055 & 1.3465 & 1.3916 & 1.4421 \\
\hline & & $\overline{\sigma_{y}}$ & 3.4464 & 3.7299 & 4.1907 & 5.0847 & 3.4464 & 3.5549 & 3.6747 & 3.8087 \\
\hline & & $\overline{\tau_{x y}}$ & 0.0056 & 0.006 & 0.0067 & 0.008 & 0.0056 & 0.0058 & 0.006 & 0.0062 \\
\hline \multirow{9}{*}{ EXP-FGM } & \multirow{3}{*}{5} & $\overline{\sigma_{x}}$ & 0.3804 & 0.3804 & 0.3804 & 0.3804 & 0.3804 & 0.3879 & 0.3954 & 0.4029 \\
\hline & & $\overline{\sigma_{y}}$ & 0.9925 & 0.9925 & 0.9925 & 0.9925 & 0.9925 & 1.0122 & 1.0321 & 1.052 \\
\hline & & $\overline{\tau_{x y}}$ & 0.002 & 0.002 & 0.002 & 0.002 & 0.002 & 0.0021 & 0.0021 & 0.0022 \\
\hline & \multirow{3}{*}{10} & $\overline{\sigma_{x}}$ & 0.7235 & 0.7235 & 0.7235 & 0.7235 & 0.7235 & 0.7366 & 0.7497 & 0.7628 \\
\hline & & $\overline{\sigma_{y}}$ & 1.8944 & 1.8944 & 1.8944 & 1.8944 & 1.8944 & 1.9286 & 1.9629 & 1.9972 \\
\hline & & $\overline{\tau_{x y}}$ & 0.0034 & 0.0034 & 0.0034 & 0.0034 & 0.0034 & 0.0035 & 0.0036 & 0.0036 \\
\hline & \multirow{3}{*}{20} & $\overline{\sigma_{x}}$ & 1.4194 & 1.4194 & 1.4194 & 1.4194 & 1.4194 & 1.4444 & 1.4694 & 1.4944 \\
\hline & & $\overline{\sigma_{y}}$ & 3.7428 & 3.7428 & 3.7428 & 3.7428 & 3.7428 & 3.8084 & 3.8741 & 3.9398 \\
\hline & & $\overline{\tau_{x y}}$ & 0.0061 & 0.0061 & 0.0061 & 0.0061 & 0.0061 & 0.0062 & 0.0064 & 0.0065 \\
\hline
\end{tabular}

spherical geometry, whereas the cylindrical panel gives the least stress results.

\section{Conclusions}

The static deflection responses of the graded structural panel were predicted numerically using a higher-order mathematical model considering the effect of porosity. Also, the effect of porosity distribution on the stress values was evaluated using the proposed mathematical model. The numerical results were obtained using an isoparametric Finite Element (FE) formulation via a computer code developed in the MATLAB environment. The model validity was established by 
Table 10. Effect of geometry on the non-dimensional stress responses of simply-supported Functionally Graded Material (FGM) structure $(a=0.1, b=0.05, h=0.1, R=10)$.

\begin{tabular}{|c|c|c|c|c|c|c|c|c|c|c|}
\hline \multirow{3}{*}{$\begin{array}{c}\text { Type of } \\
\text { FGM }\end{array}$} & \multirow{3}{*}{ Geometry } & \multirow{3}{*}{ Stress } & \multicolumn{8}{|c|}{ Porosity index $(\lambda)$ and distribution } \\
\hline & & & \multicolumn{4}{|c|}{ Even } & \multicolumn{4}{|c|}{ Uneven } \\
\hline & & & $\mathbf{0}$ & 0.1 & 0.2 & 0.3 & 0 & 0.1 & 0.2 & 0.3 \\
\hline \multirow{9}{*}{ PWL-FGM } & \multirow{3}{*}{ Cylindrical } & $\overline{\sigma_{x}}$ & 1.2812 & 1.4132 & 1.6499 & 2.2454 & 1.2812 & 1.3254 & 1.3746 & 1.4304 \\
\hline & & $\overline{\sigma_{y}}$ & 2.7668 & 3.0493 & 3.5556 & 4.825 & 2.7668 & 2.8619 & 2.9681 & 3.0889 \\
\hline & & $\overline{\tau_{x y}}$ & 0.0053 & 0.0058 & 0.0068 & 0.009 & 0.0053 & 0.0055 & 0.0057 & 0.006 \\
\hline & \multirow{3}{*}{ Spherical } & $\overline{\sigma_{x}}$ & 1.2845 & 1.417 & 1.6548 & 2.2528 & 1.2845 & 1.3289 & 1.3783 & 1.4345 \\
\hline & & $\overline{\sigma_{y}}$ & 2.7673 & 3.05 & 3.5565 & 4.8264 & 2.7673 & 2.8624 & 2.9687 & 3.0896 \\
\hline & & $\overline{\tau_{x y}}$ & 0.0053 & 0.0058 & 0.0068 & 0.009 & 0.0053 & 0.0055 & 0.0057 & 0.0059 \\
\hline & \multirow{3}{*}{ Elliptical } & $\overline{\sigma_{x}}$ & 1.2829 & 1.4151 & 1.6524 & 2.2491 & 1.2829 & 1.3271 & 1.3765 & 1.4325 \\
\hline & & $\overline{\sigma_{y}}$ & 2.767 & 3.0496 & 3.556 & 4.8257 & 2.767 & 2.8622 & 2.9684 & 3.0893 \\
\hline & & $\overline{\tau_{x y}}$ & 0.0053 & 0.0058 & 0.0068 & 0.009 & 0.0053 & 0.0055 & 0.0057 & 0.0059 \\
\hline \multirow{9}{*}{ SIG-FGM } & \multirow{3}{*}{ Cylindrical } & $\overline{\sigma_{x}}$ & 1.1334 & 1.2277 & 1.3804 & 1.6746 & 1.1334 & 1.1701 & 1.2107 & 1.2562 \\
\hline & & $\overline{\sigma_{y}}$ & 2.4491 & 2.6512 & 2.978 & 3.6069 & 2.4491 & 2.5281 & 2.6157 & 2.7139 \\
\hline & & $\overline{\tau_{x y}}$ & 0.0047 & 0.005 & 0.0056 & 0.0067 & 0.0047 & 0.0048 & 0.005 & 0.0052 \\
\hline & \multirow{3}{*}{ Spherical } & $\overline{\sigma_{x}}$ & 1.1362 & 1.2309 & 1.3841 & 1.6794 & 1.1362 & 1.1731 & 1.2139 & 1.2596 \\
\hline & & $\overline{\sigma_{y}}$ & 2.4496 & 2.6518 & 2.9788 & 3.6079 & 2.4496 & 2.5287 & 2.6163 & 2.7145 \\
\hline & & $\overline{\tau_{x y}}$ & 0.0047 & 0.005 & 0.0056 & 0.0067 & 0.0047 & 0.0048 & 0.005 & 0.0052 \\
\hline & \multirow{3}{*}{ Elliptical } & $\overline{\sigma_{x}}$ & 1.1348 & 1.2293 & 1.3822 & 1.677 & 1.1348 & 1.1716 & 1.2123 & 1.2579 \\
\hline & & $\overline{\sigma_{y}}$ & 2.4493 & 2.6515 & 2.9784 & 3.6074 & 2.4493 & 2.5284 & 2.616 & 2.7142 \\
\hline & & $\overline{\tau_{x y}}$ & 0.0047 & 0.005 & 0.0056 & 0.0067 & 0.0047 & 0.0048 & 0.005 & 0.0052 \\
\hline \multirow{9}{*}{ EXP-FGM } & \multirow{3}{*}{ Cylindrical } & $\overline{\sigma_{x}}$ & 1.2309 & 1.2309 & 1.2309 & 1.2309 & 1.2309 & 1.2529 & 1.275 & 1.2971 \\
\hline & & $\overline{\sigma_{y}}$ & 2.6584 & 2.6584 & 2.6584 & 2.6584 & 2.6584 & 2.7058 & 2.7533 & 2.8008 \\
\hline & & $\overline{\tau_{x y}}$ & 0.0051 & 0.0051 & 0.0051 & 0.0051 & 0.0051 & 0.0052 & 0.0053 & 0.0054 \\
\hline & \multirow{3}{*}{ Spherical } & $\overline{\sigma_{x}}$ & 1.2339 & 1.2339 & 1.2339 & 1.2339 & 1.2339 & 1.2561 & 1.2782 & 1.3004 \\
\hline & & $\overline{\sigma_{y}}$ & 2.6589 & 2.6589 & 2.6589 & 2.6589 & 2.6589 & 2.7063 & 2.7537 & 2.8013 \\
\hline & & $\overline{\tau_{x y}}$ & 0.0051 & 0.0051 & 0.0051 & 0.0051 & 0.0051 & 0.0052 & 0.0053 & 0.0054 \\
\hline & \multirow{3}{*}{ Elliptical } & $\overline{\sigma_{x}}$ & 1.2324 & 1.2324 & 1.2324 & 1.2324 & 1.2324 & 1.2545 & 1.2766 & 1.2988 \\
\hline & & $\overline{\sigma_{y}}$ & 2.6586 & 2.6586 & 2.6586 & 2.6586 & 2.6586 & 2.706 & 2.7535 & 2.801 \\
\hline & & $\overline{\tau_{x y}}$ & 0.0051 & 0.0051 & 0.0051 & 0.0051 & 0.0051 & 0.0052 & 0.0053 & 0.0054 \\
\hline
\end{tabular}

comparing the results with deflection and stress values for a different graded structure without porosity including the grading pattern. The validation study pointed to the viability of the present higher-order FE model and a few examples were solved for different influential parameters. A list of important conclusions is highlighted below as per the individual/combined cases.:

- The static deflection and the stress results were lower for SIG-FGM than those for PWL-FGM and
EXP-FGM without porosity, whereas the highest deflection and stress values were achieved in the case of PWL-FGM. The difference between the results obtained for the SIG and PWL graded structures in this case was found to be $9-15 \%$ for different influencing parameters;

- Conversely, the EXP-FGM structure was capable of sustaining a good amount of deflection including the effect of porosity. In this case, maximum values (deflection and stress) were obtained for the PWL- 
FGM. For various design parameters, the percentage difference between the computed results for EXP and PWL graded structures lied in the range of $10-$ $59 \%$;

- The results exhibited the smaller variation of deflection and/or stress for the uneven type of porosity distribution than the even kind of porosity distribution;

- The design parameters including aspect ratio, thickness ratio, power-law exponent, geometry, support conditions, and curvature ratios were found to affect the static deflection and stress results of the Functionally Graded (FG) porous structures considerably;

- It is important to note that the even type of porosity distribution shows insignificant variation between the normal stress values $\left(\sigma_{x}\right.$ and $\left.\sigma_{y}\right)$, i.e., within the range of $10^{-5}$ to $10^{-9}$, for EXP-FG panel while the properties of $\mathrm{Al}_{2} \mathrm{O}_{3} / \mathrm{Al}$ materials are adopted.

\section{Nomenclature}

$P \quad$ Effective material property of FG

$P^{c}, P^{m} \quad$ Corresponding properties of the ceramic and metal constituents, respectively

$\alpha_{z} \quad$ Random point in the thickness direction

$n_{z} \quad$ Power-law exponent

$\lambda \quad$ Porosity index

$c, m \quad$ Ceramic and metal constituents

$V_{f_{c}}, V_{f_{m}} \quad$ Volume fractions of ceramic and metal constituents, respectively

$a, b, h \quad$ Length, width and thickness of the FG panel, respectively

$R \alpha_{x}, R \alpha_{y} \quad$ Radius of curvature along $\alpha_{x}$ and $\alpha_{y}$-axis of the panel, respectively

$\alpha_{x x}, \alpha_{y y}, \alpha_{z z}$ Global and mid-plane displacement field along $\alpha_{x}, \alpha_{y}$, and $\alpha_{z}$-direction, respectively

$\alpha_{x x_{0}}, \alpha_{y y_{0}}, \quad$ Mid-plane displacement field along $\alpha_{z z_{0}} \quad \alpha_{x}, \alpha_{y}$, and $\alpha_{z}$-direction, respectively

$\psi_{x}, \psi_{y} \quad$ Rotation of transverse normal to the mid-plane about the $\alpha_{y}$ and $\alpha_{x}$-axis, respectively

$\alpha_{x x_{0}}^{*}, \alpha_{y y_{0}}^{*}, \quad$ Higher-order terms of Taylor's series $\psi_{x}^{*}, \psi_{y}^{*} \quad$ expansion

$\alpha_{z}^{2}, \alpha_{z}^{3} \quad$ Square and cubic thickness coordinates, respectively

$\varepsilon_{l}$
$\left[T_{l}\right]_{5 \times 20} \quad$ Linear thickness coordinate matrix

$\left\{\overline{\varepsilon_{l}}\right\}_{20 \times 1} \quad$ Mid-plane strain terms matrix

$\left\{\delta_{0}\right\} \quad$ Global displacement field vector

$\left\{\delta_{0_{i}}\right\} \quad$ Mid-plane displacement field vector for $i$ th node

$[N] \quad$ Nodal shape function

$\left\{\bar{\varepsilon}_{l}\right\} \quad$ Mid-plane strain term

$[B]_{20 \times 9} \quad$ Product form of shape functions and the differential operators

$\{\sigma\},[Q],\{\varepsilon\}$ Stress, reduced stiffness matrix, and strain vector, respectively

$U \quad$ Total strain energy

$[D] \quad$ Material property matrix

W Workdone

$q \quad$ Applied transverse load

[F] Force vector

$[K] \quad$ Global stiffness matrix

$\delta, \Pi \quad$ Variation and total energy functionals, respectively

$S \quad$ Thickness ratio

O Aspect ratio

$R / h \quad$ Curvature ratio

$w \quad$ Actual deflection

$\bar{w} \quad$ Non-dimensional deflection

$E^{c}, E^{m} \quad$ Young's modulus of ceramic and metal, respectively

$\mu \quad$ Poisson's ratio

$\bar{\sigma} \quad$ Non-dimensional stress

$\sigma \quad$ Actual stress

$\tau_{x y} \quad$ Actual shear stress

$\overline{\tau_{x y}} \quad$ Non-dimensional shear stress

\section{Abbreviations}

HSDT Higher-order Shear Deformation Theory

FSDT First-order Shear Deformation Theory

SDT Generalized Shear Deformation Theory

HySDT Hyperbolic Shear Deformation Theory

TrSDT Trigonometric Shear Deformation Theory

SGT Strain Gradient Theory

\section{References}

1. Chi, S.-H. and Chung, Y.-L. "Mechanical behavior of functionally graded material plates under transverse load - Part I: Analysis", Int. J. Solids Struct., 43, pp. 3657-3674 (2006). 
2. Wang, Y.Q. and Zu, J.W. "Vibration behaviors of functionally graded rectangular plates with porosities and moving in thermal environment", Aerosp. Sci. Technol., 69, pp. 550-562 (2017).

3. Kashtalyan, M. "Three-dimensional elasticity solution for bending of functionally graded rectangular plates", Eur. J. Mech. A/Solids, 23(5), pp. 853-864 (2004).

4. Zenkour, A.M. "Generalized shear deformation theory for bending analysis of functionally graded plates", Appl. Math. Model., 30(1), pp. 67-84 (2006).

5. Chung, Y.-L. and Chen, W.-T. "Bending behavior of FGM-coated and FGM-undercoated plates with two simply supported opposite edges and two free edges", Compos. Struct., 81, pp. 157-167 (2007).

6. Ben-Oumrane, S., Abedlouahed, T., Ismail, M., Mohamed, B.B., Mustapha, M., and Abbas, A.B.El. "A theoretical analysis of flexional bending of $\mathrm{Al} / \mathrm{Al}_{2} \mathrm{O}_{3} \mathrm{~S}-$ FGM thick beams", Comput. Mater. Sci., 44(4), pp. 1344-1350 (2009).

7. Bhandari, M. and Purohit, K. "Static response of functionally graded material plate under transverse load for varying aspect ratio", Int. J. Met., 2014, pp. 1-11 (2014).

8. Brischetto, S., Leetsch, R., Carrera, E., Wallmersperger, T., and Krplin, B. "Thermomechanical bending of functionally graded plates", $J$. Therm. Stress., 31(3), pp. 286-308 (2008).

9. Filippi, M., Carrera, E., and Zenkour, A.M. "Static analyses of FGM beams by various theories and finite elements", Compos. Part B Eng., 72, pp. 1-9 (2015).

10. Thai, H.-T. and Choi, D.-H. "A simple first-order shear deformation theory for the bending and free vibration analysis of functionally graded plates", Compos. Struct., 101, pp. 332-340 (2013).

11. Talha, M. and Singh, B.N. "Static response and free vibration analysis of FGM plates using higher order shear deformation theory", Appl. Math. Model., 34(12), pp. 3991-4011 (2010).

12. Zhao, Z., Feng, C., Wang, Y., and Yang, J. "Bending and vibration analysis of functionally graded trapezoidal nanocomposite plates reinforced with graphene nanoplatelets (GPLs)", Compos. Struct., 180, pp. 799-808 (2017).

13. Bellifa, H., Benrahou, K.H., Hadji, L., Houari, M.S.A., and Tounsi, A. "Bending and free vibration analysis of functionally graded plates using a simple shear deformation theory and the concept the neutral surface position", J. Brazilian Soc. Mech. Sci. Eng., 38(1), pp. 265-275 (2016).

14. Sherafat, M.H., Ovesy, H.R., and Ghannadpour, S.A.M. "Buckling analysis of functionally graded plates under mechanical loading using higher order functionally graded strip", Int. J. Struct. Stab. Dyn., 13(6), pp. 1-13 (2013).

15. Thai, H.-T., Vo, T.P., Bui, T.Q., and Nguyen, T.-K. "A quasi-3D hyperbolic shear deformation theory for functionally graded plates", Acta Mech., 225(3), pp. 951-964 (2014).
16. Vu, T.V., Nguyen, N.H., Khosravifard, A., Hematiyan, M.R., Tanaka, S., and Bui, T.Q. "A simple FSDTbased meshfree method for analysis of functionally graded plates", Eng. Anal. Bound. Elem., 79, pp. 1-12 (2017).

17. Mirzaei, M. and Kiani, Y. "Free vibration of functionally graded carbon-nanotube-reinforced composite plates with cutout", Beilstein J. Nanotechnol., 7(1), pp. 511-523 (2016).

18. Kiani, Y. "Free vibration of FG-CNT reinforced composite spherical shell panels using Gram-Schmidt shape functions", Compos. Struct., 159, pp. 368-381 (2017).

19. Hajmohammad, M.H., Azizkhani, M.B., and Kolahchi, R. "Multiphase nanocomposite viscoelastic laminated conical shells subjected to magneto-hygrothermal loads: Dynamic buckling analysis", Int. J. Mech. Sci, 137, pp. 205-213 (2018).

20. Hajmohammad, M.H., Farrokhian, A., and Kolahchi, R. "Smart control and vibration of viscoelastic actuator-multiphase nanocomposite conical shellssensor considering hygrothermal load based on layerwise theory", Aerosp. Sci. Technol. Technol., 78, pp. 260-270 (2018).

21. Besseghier, A., Houari, M.S.A., Tounsi, A., and Mahmoud, S.R. "Free vibration analysis of embedded nanosize FG plates using a new nonlocal trigonometric shear deformation theory", Smart Struct. Syst., 19(6), pp. 601-614 (2017).

22. Abualnour, M., Houari, M.S.A., Tounsi, A., Bedia, E.A.A., and Mahmoud, S.R. "A novel quasi-3D trigonometric plate theory for free vibration analysis of advanced composite plates", Compos. Struct., 184, pp. 688-697 (2018).

23. Thai, C.H., Tran, T.D., and Phung-Van, P. "A size-dependent moving Kriging meshfree model for deformation and free vibration analysis of functionally graded carbon nanotube-reinforced composite nanoplates", Eng. Anal. Bound. Elem., 115, pp. 52-63 (2020).

24. Belkhodja, Y., Ouinas, D., Zaoui, F.Z., and Fekirini, H. "An exponential-trigonometric higher order shear deformation theory (HSDT) for bending, free vibration, and buckling analysis of Functionally Graded Materials (FGMs) plates", Adv. Compos. Lett., 29, p. 096369351987573 (2020).

25. Do, V.T., Pham, V.V., and Nguyen, H.N. "On the development of refined plate theory for static bending behavior of functionally graded plates", Math. Probl. Eng., 2020, pp. 1-13 (2020).

26. Zhang, P., Qing, H., and Gao, C. "Exact solutions for bending of Timoshenko curved nanobeams made of functionally graded materials based on stress-driven nonlocal integral model", Compos. Struct., 245, p. 112362 (2020).

27. Ghassabi, M., Talebitooti, R., and Zarastvand, M.R. "State vector computational technique for three- 
dimensional acoustic sound propagation through doubly curved thick structure", Comput. Methods Appl. Mech. Eng., 352, pp. 324-344 (2019).

28. Ghassabi, M., Zarastvand, M.R., and Talebitooti, R. "Investigation of state vector computational solution on modeling of wave propagation through functionally graded nanocomposite doubly curved thick structures", Eng. Comput., 36(4), pp. 1-17 (2019).

29. Talebitooti, R., Zarastvand, M., and Rouhani, A.S. "Investigating Hyperbolic Shear Deformation Theory on vibroacoustic behavior of the infinite functionally graded thick plate", Lat. Am. J. Solids Struct., 16(1), pp. 1-17 (2019).

30. Talebitooti, R., Johari, V., and Zarastvand, M. "Wave transmission across laminated composite plate in the subsonic flow investigating two-variable refined plate theory", Lat. Am. J. Solids Struct., 15(5), pp. 1-20 (2018).

31. Talebitooti, R., Zarastvand, M., and Gohari, H. "Investigation of power transmission across laminated composite doubly curved shell in the presence of external flow considering shear deformation shallow shell theory", J. Vib. Control, 24(19), pp. 4492-4504 (2018).

32. Talebitooti, R. and Zarastvand, M.R. "Vibroacoustic behavior of orthotropic aerospace composite structure in the subsonic flow considering the third order shear deformation theory", Aerosp. Sci. Technol., 75, pp. 227-236 (2018).

33. Talebitooti, R., Zarastvand, M.R., and Gohari, H.D. "The influence of boundaries on sound insulation of the multilayered aerospace poroelastic composite structure", Aerosp. Sci. Technol., 80, pp. 452-471 (2018).

34. Balubaid, M., Tounsi, A., Dakhel, B., and Mahmoud, S.R. "Free vibration investigation of FG nanoscale plate using nonlocal two variables integral refined plate theory", Comput. Concr., 24(6), pp. 579-586 (2019).

35. Tounsi, A., Al-Dulaijan, S.U., Al-Osta, M.A., Chikh, A., Al-Zahrani, M.M., Sharif, A., and Tounsi, A. "A four variable trigonometric integral plate theory for hygro-thermo-mechanical bending analysis of AFG ceramic-metal plates resting on a two-parameter elastic foundation", Steel Compos. Struct., 34(4), pp. 511-524 (2020).

36. Bellal, M., Hebali, H., Heireche, H., Bousahla, A.A., Tounsi, A., Bourada, F., Mahmoud, S.R., Bedia, E.A.A., and Tounsi, A. "Buckling behavior of a singlelayered graphene sheet resting on viscoelastic medium via nonlocal four-unknown integral model", Steel Compos. Struct., 34(5), pp. 643-655 (2020).

37. Rahmani, M.C., Kaci, A., Bousahla, A.A., Bourada, F., Tounsi, A., Bedia, E.A.A., Mahmoud, S.R., Benrahou, K.H., and Tounsi, A. "Influence of boundary conditions on the bending and free vibration behavior of FGM sandwich plates using a four-unknown refined integral plate theory", Comput. Concr., 25(3), pp. 225-244 (2020).
38. Chaabane, L.A., Bourada, F., Sekkal, M., Zerouati, S., Zaoui, F.Z., Tounsi, A., Derras, A., Bousahla, A.A., and Tounsi, A. "Analytical study of bending and free vibration responses of functionally graded beams resting on elastic foundation", Struct. Eng. Mech., 71(2), pp. 185-196 (2019).

39. Boutaleb, S., Benrahou, K.H., Bakora, A., Algarni, A., Bousahla, A.A., Tounsi, A., Tounsi, A., and Mahmoud, S.R. "Dynamic analysis of nanosize FG rectangular plates based on simple nonlocal quasi 3D HSDT", Adv. Nano Res., 7(3), pp. 191-208 (2019).

40. Boussoula, A., Boucham, B., Bourada, M., Bourada, F., and Tounsi, A. "A simple nth-order shear deformation theory for thermomechanical bending analysis of different configurations of FG sandwich plates", Smart Struct. Syst., 25(2), pp. 197-218 (2020).

41. Refrafi, S., Bousahla, A.A., Bouhadra, A., Menasria, A., Bourada, F., Tounsi, A., Bedia, E.A.A., Mahmoud, S.R., Benrahou, K.H., and Tounsi, A. "Effects of hygro-thermo-mechanical conditions on the buckling of FG sandwich plates resting on elastic foundations", Comput. Concr., 25(4), pp. 311-325 (2020).

42. Motezaker, M., Jamali, M., and Kolahchi, R. "Application of differential cubature method for nonlocal vibration, buckling and bending response of annular nanoplates integrated by piezoelectric layers based on surface-higher order nonlocal-piezoelasticity theory", J. Comput. Appl. Math., 369, p. 112625 (2020).

43. Kolahchi, R., Hosseini, H., Fakhar, M.H., Taherifar, R., and Mahmoudi, M. "A numerical method for magneto-hygro-thermal postbuckling analysis of defective quadrilateral graphene sheets using higher order nonlocal strain gradient theory with different movable boundary conditions", Comput. Math. with Appl., 78(6), pp. 2018-2034 (2019).

44. Keshtegar, B., Farrokhian, A., Kolahchi, R., and Trung, N.-T. "Dynamic stability response of truncated nanocomposite conical shell with magnetostrictive face sheets utilizing higher order theory of sandwich panels", Eur. J. Mech. - A/Solids, 82, p. 104010 (2020).

45. Farokhian, A. and Kolahchi, R. "Frequency and instability responses in nanocomposite plate assuming different distribution of CNTs", Struct. Eng. Mech., 73(5), pp. 555-563 (2020).

46. Keshtegar, B., Bagheri, M., Meng, D., Kolahchi, R., and Trung, N.-T. "Fuzzy reliability analysis of nanocomposite $\mathrm{ZnO}$ beams using hybrid analyticalintelligent method", Eng. Comput., pp. 1-16 (2020).

47. Chen, D., Yang, J., and Kitipornchai, S. "Elastic buckling and static bending of shear deformable functionally graded porous beam", Compos. Struct., 133, pp. 54-61 (2015).

48. Kim, J., Żur, K.K., and Reddy, J.N. "Bending, free vibration, and buckling of modified couples stressbased functionally graded porous micro-plates", Compos. Struct., 209, pp. 879-888 (2019). 
49. She, G.L., Yuan, F.G., Ren, Y.R., Liu, H.B., and Xiao, W.S. "Nonlinear bending and vibration analysis of functionally graded porous tubes via a nonlocal strain gradient theory", Compos. Struct., 203, pp. 614-623 (2018).

50. Sahmani, S., Aghdam, M.M., and Rabczuk, T. "Nonlinear bending of functionally graded porous micro/nano-beams reinforced with graphene platelets based upon nonlocal strain gradient theory", Compos. Struct., 186, pp. 68-78 (2018).

51. Berghouti, H., Bedia, E.A.A., Benkhedda, A., and Tounsi, A. "Vibration analysis of nonlocal porous nanobeams made of functionally graded material", Adv. Nano Res., 7(5), pp. 351-364 (2019).

52. Bourada, F., Bousahla, A.A., Bourada, M., Azzaz, A., Zinata, A., and Tounsi, A. "Dynamic investigation of porous functionally graded beam using a sinusoidal shear deformation theory", Wind Struct., 28(1), pp. 19-30 (2019).

53. Addou, F.Y., Meradjah, M., Bousahla, A.A., Benachour, A., Bourada, F., Tounsi, A., and Mahmoud, S.R. "Influences of porosity on dynamic response of FG plates resting on Winkler/Pasternak/Kerr foundation using quasi 3D HSDT", Comput. Concr., 24(4), pp. 347-367 (2019).

54. Kaddari, M., Kaci, A., Bousahla, A.A., Tounsi, A., Bourada, F., Tounsi, A., Bedia, E.A.A., and Al-Osta, M.A. "A study on the structural behaviour of functionally graded porous plates on elastic foundation using a new quasi-3D model: Bending and free vibration analysis", Comput. Concr., 25(1), pp. 37-57 (2020).

55. Amir, M. and Talha, M. "Nonlinear vibration characteristics of shear deformable functionally graded curved panels with porosity including temperature effects", Int. J. Press. Vessel. Pip., 172, pp. 28-41 (2019).

56. Avcar, M. "Free vibration of imperfect sigmoid and power law functionally graded beams", Steel Compos. Struct., 30(6), pp. 603-615 (2019).

57. Kar, V.R. and Panda, S.K. "Nonlinear free vibration of functionally graded doubly curved shear deformable panels using finite element method", J. Vib. Control, 22(7), pp. 1935-1949 (2016).

58. Reddy, J.N., Mechanics of Laminated Composite Plates and Shells: Theory and Analysis, 2nd Edn., CRC Press, New York (2004).

59. Cook, R.D., Malkus, D.S., Plesha, M.E., and Witt, R.J., Concepts and Applications of Finite Element
Analysis, 4th Edn., John Wiley and Sons, Singapore (2009).

60. Daouadji, T.H., Tounsi, A., and Bedia, E.A.A. "Analytical solution for bending analysis of functionally graded plates", Sci. Iran., 20(3), pp. 516-523 (2013).

\section{Biographies}

Prashik Malhari Ramteke is the leading author and pursuing PhD at the Department of Mechanical Engineering of National Institute of Technology Rourkela. He has completed his post graduate studies in the field of structural modelling and analysis. Currently, he is working in the field of nonlinear modeling of functionally graded material structure using the finite element technique using the numerical techniques. This research is a derivative of one of the outcomes of the relevant research, i.e., influences of different grading patterns including effect of porosities on their final responses.

Kulamani Mehar received his $\mathrm{PhD}$ from the National Institute of Technology Rourkela in 2019. He is currently working as an Assistant Professor at the Department of Mechanical Engineering, Madanapalle Institute of Technology and Science. His current research interest includes graded material modeling, CNT, smart material, and composite material modeling and analysis.

Nitin Sharma is working as an Associate Professor (Grade-I) in the School of Mechanical Engineering, KIIT (Deemed to be University) Bhubaneswar. His areas of interest include vibroacoustic analysis, finite element methods, boundary element technique, hybrid composite structures, and grading influences on structural stiffness.

Subrata Kumar Panda received his PhD from IIT Kharagpur, India in 2009. He is working as an Associate Professor at the Department of Mechanical Engineering, NIT, Rourkela. His current research interest includes nonlinear solid mechanics, smart composite structures, nonlinear FEM, experimental vibrations, functionally graded materials, SMA, PZT and magnetostrictive material, and bio-mechanical analysis of functional materials. 